\title{
The Intergenerational Effects of Language Proficiency on Child Health Outcomes*
}

\author{
Nicole Black ${ }^{1}$ and Johannes S. Kunz ${ }^{2}$
}

\begin{abstract}
:
Language proficiency is a crucial skill for immigrants that influences their social integration and their children's development. This study examines the intergenerational effects of limited English proficiency (LEP) on children's health and health care utilisation. We use 10 years of Australian administrative health care records linked to survey data, and a structural break in language acquisition, based on the parent's age at arrival into Australia. We find that parental LEP has a strong and positive effect on children's health care costs, but no effect on their physical or mental health. A lack of parent social networks is a plausible explanation.
\end{abstract}

Keywords: Second-Generation, Language Proficiency, Health Outcomes, Health Care Utilisation, Parenting Styles, Social Networks.

JEL Codes: F22, I12, J13, J24, J61, J62.

Acknowledgments: We thank Daniel Auer, Andreas Beerli, Pietro Biroli, Andrew Clarke, Christina Felfe, Denzil Fiebig, Andrew Jones, David Johnston, Asad Islam, Ingo Isphording, Nico Salamanca, Michael Shields, Michael Siegenthaler, Kevin Staub, Steve Stillman, Jan Van Ours, and participants of iHEA (Basel), Workshop on the Economics of Health and Wellbeing (Hepburn Springs), Sinergia Workshop (Zurich), SKILS Workshop (Engelberg) as well as seminar participants at Bristol, Melbourne Institute, Monash University, London City University, and York for thoughtful comments.

${ }^{1}$ Centre for Health Economics, Monash University, 900 Dandenong Road, 3145 Caulfield East, Vic Australia, T: +61 39905 0752, nicole.black@monash.edu

${ }^{2}$ Centre for Health Economics, Monash University, 900 Dandenong Road, 3145 Caulfield East, Vic Australia, T: +61 39905 0752, jo-hannes.kunz@monash.edu

(C) 2019 Nicole Black and Johannes Kunz

All rights reserved. No part of this paper may be reproduced in any form, or stored in a retrieval system, without the prior written permission of the author.

monash.edu/ businesseconomics

ABN 12377614012 CRICOS Provider No. 00008C

AACSB

ACCREDITED 


\section{Introduction}

Childhood health has long-lasting impacts on an individual's health and economic prosperity. In fact, there is mounting evidence that better health in childhood is linked to better educational achievement, labour market outcomes, and health in adulthood (e.g., Currie et al., 2010; Case, Fertig and Paxson, 2005). What is worrying is that there is a socioeconomic gradient in childhood health - that is, children who grow up in poorer or lower educated families are less likely to be healthy (e.g., Case, Lubotsky and Paxson, 2002; Currie and Stabile, 2003). Despite the strong correlation between parental education and child health, recent studies indicate that additional years of parental education may have little causal impact on children's health (e.g., Lindeboom, Llena-Nozal and van Der Klaauw, 2009). It is argued that certain specific skills (such as the ability to process information) may matter more for promoting good health, than the simple quantity of schooling (e.g., Cutler and Lleras-Muney, 2010). This calls for a greater understanding of what specific skills of parents influence their child's health and how that occurs. In this study, we contribute to this understanding by focussing on the influence of parental language skills among immigrant families.

Investigation into the intergenerational effect of language skills among immigrants is of particular importance for at least three reasons. First, the number of international immigrants continues to grow rapidly, reaching 258 million globally in 2017, and a majority of immigrants settle in high-income countries (UN, 2017). Given the increasing number of children born to immigrant parents, and the importance of their early years for their future socioeconomic trajectories, it is important to understand how intergenerational skills affect immigrant communities. Second, language proficiency is arguably the most relevant skill for immigrants to be able to process information. Despite improvements in their situations, many immigrants remain some of the most vulnerable members of society. Therefore, parents' limited language skills can compound already existing disadvantages that children of immigrants face. Third, if children of low-skilled immigrants use more health care services, or have greater barriers to accessing needed health care, then there may be implications for both the financing and the equitable utilisation of public health care services.

A growing literature shows that there are important intergenerational effects of language skills. For example, parental language skills are positively related to children's English speaking proficiency, educational attainment, and labour market outcomes (among many others, Bleakley and Chin, 2008; Guven and Islam, 2015; Casey and Dustmann, 2008; Kunz, 2016; Groger and Trejo, 2002). However, there is limited understanding of how language skills may be part of the intergenerational effects on children's health outcomes, or health care utilisation. Because mental and physical health are key inputs into a child's human capital development, any (language) barriers to health care and good health could have life-long implications for the prosperity and wellbeing of children. 
In this paper, we provide evidence on the effects of limited English proficiency (hereafter LEP) among immigrant parents on the child's utilisation of health services and health status. We rely on a structural break in language acquisition that occurs when immigrants arrive in the host country after early adolescence as a plausibly exogenous source of variation in language proficiency (Bleakley and Chin, 2004). By using data from Australia, which has universal public health insurance, we mitigate important selection issues arising from insurance coverage (Dillender, 2017). Australia has a large share of international immigrants: $28 \%$ of the population were born overseas and a further $21 \%$ had at least one parent born overseas (ABS, 2016). There are over 300 languages spoken in Australian homes, and about one in five Australians speak a language other than English at home (ABS, 2016). This makes Australia a natural setting for studying the health effects of English language skills among immigrants.

We compile a dataset that has three key advantages for examining this issue. First, our data come from the nationally representative Longitudinal Study of Australian Children (LSAC), which includes detailed measures of the child's health status along with an extensive set of parent's characteristics and parenting behaviours. Second, this dataset is linked to 10 years of administrative records of all primary health care services and pharmaceuticals provided under Medicare, Australia's public health insurance scheme. All of the children in our study are covered by Medicare (and have been since birth). We concentrate on children's health care utilisation (measured in AUD) as our primary outcome measure because it is complete, objective and measured uniformly across all children in Australia. It has the advantage of allowing the impact of language skills to be quantified in dollar terms, and therefore contributes uniquely to the understanding of the cost implications (to the government) of limited language skills. Third, we use a measure of parent's language proficiency that is assessed by the interviewer, an arguably more objective measure than the commonly used self-reported measure of language proficiency.

One key challenge in determining the causal impact of parent's limited language proficiency on children's health outcomes is that there are likely to be compositional differences between parents with and without LEP (such as ability, motivation to learn, and assimilation into the host country). These may be correlated with both their language skills and health investments and behaviours. We use a number of complementary approaches to address this concern. Most importantly is ethnicity and the age at arrival which, as we show, are the main variables governing selection. Additionally, we report several key facts suggesting a causal interpretation. These include: estimates from ordinary least squares (OLS) regressions with carefully selected control variables; testing for the remaining balance in other observed parental characteristics by language proficiency (Pei, Pischke and Schwandt, 2018); bound analyses to gauge the extent of selection on unobserved (omitted) characteristics (Altonji, Elder and Taber, 2008, 2005b,a; Oster, 2017); and, an instrumental variables (IV) estimator. To construct an instrument for whether a parent has LEP, we leverage the interaction of two (arguably exogenous) sources of variation: heterogeneity in parent's country of origin; and, age at arrival into Australia. This approach, first developed by Bleakley and Chin (2004), is based on the 'critical period hypothesis' of language acquisition 
(Lenneberg, 1967), which suggests that a person can learn a language much more easily if they are exposed to it within the 'critical period' (i.e. their childhood). We use immigrants from English-speaking countries to difference-out non-language effects of age at arrival (which resembles a difference-in-differences approach). Therefore, identification is based on LEP differences between arriving before and after the 'critical period', and between immigrants from English and non-English speaking countries. We further complement our analysis with rigorous robustness testing.

Our raw data indicate that a parent's LEP is associated with significantly higher child health care costs (by around 33\%) over a 10-year period (2004-2013). After taking account of the selection by country of birth and age at arrival, results from all our analyses consistently demonstrate a strong and robust positive correlation persists between LEP and health care costs, even after controlling for selection on observed and unobserved characteristics. Our OLS and IV indicate that parental LEP increases children's health care costs by about $25-90 \%$ over a 10 -year period, which equates to roughly $\$ 60-228$ per year (in 2015 AUD) per child. Despite the sizeable effect on health care utilisation, we find no evidence that parental LEP has any significant impact on the physical or mental health of children. This is a positive finding that speaks to the effectiveness of Australia's publicly funded universal health care system in ensuring that, at least for children, health is not dependent on parental language skills. Of concern, however, is that the higher Medicare costs arising from limited language skills appear to indicate an overconsumption of health services and an inefficient use of health system resources. Both medical services and subsidised prescription drugs contribute to the higher cost, but medical services are the largest contributors.

We then investigate the possibility that these higher costs are due to over-servicing by physicians. We do this by examining the effect of language proficiency on services that can only be prescribed by the physician (e.g. pathology and diagnostic tests). We uncover no evidence of over-servicing by the physician. Rather, higher medical service use is driven exclusively by more GP visits. Investigating possible demand-side mechanisms (including socioeconomic status, parental uncertainty, parenting styles, and communication with GPs), we find reliance on the GP for parenting information may be a likely explanation, particularly if there is a GP in the local area who speaks the same language as the parent. This suggests, programs that support immigrants and their young families, for example, through parent networking groups, or the provision of parenting information in various languages, may produce economically meaningful returns. Our results also indicate that medical cost savings are one overlooked benefit of English language training; this may improve the economic argument for providing free or subsidised language classes.

\section{Background}

Parental language skills may determine child health outcomes in much the same way that education affects the production of health (Grossman, 1972; Cutler and Lleras-Muney, 2006). Language skills can 
affect the efficiency of health production directly, for example through improved understanding of health information, ability to follow medical instructions, and understanding nutrition and medicine labels: in other words, by affecting "health literacy". Language skills, also may influence the production of health indirectly by affecting the financial resources that are available to afford healthy lifestyles, e.g. through employment, wages and occupation, and by affecting one's social networks and peers, which can influence health behaviours. Overall, we would expect parental LEP to be associated with poorer child health and a greater need for health care. Indeed, there is some evidence to suggest that LEP causally reduces selfassessed health among adult immigrants (e.g., Aoki and Santiago, 2018; Guven and Islam, 2015; Clarke and Isphording, 2017). However, our understanding of the intergenerational effects of language skills on child health is very limited. ${ }^{1}$

In terms of health care utilisation, the impact of language skills is a priori less clear: it involves both demand- and supply-side considerations. If limited language skills increase barriers to accessing health care services, then inequities in health care utilisation (i.e. underutilisation for a given health need) may arise. One obvious barrier is a lack of health insurance. Dillender (2017) showed that in the U.S., LEP reduced access to employer-sponsored insurance, as well as to Medicaid coverage (despite eligibility) for adults and children. Several studies have shown that, consistent with having less health insurance, LEP is associated with reduced access to needed health services in the U.S. (e.g. Weinick and Krauss, 2000; Jacobs et al., 2006). However, even under a universal health insurance system, language barriers can make it difficult to navigate the system and to access its services. The extent of such barriers depends on the social support networks available to the parent (Aizer and Currie, 2004) and on the quality of translator services available within the health system. Bias or discrimination on the part of the physician also may lead to less equitable health care use (Nelson, 2002).

On the other hand, there are several reasons why LEP might lead to greater use of health care services for a given health need. A lack of health information or knowledge may increase a parent's uncertainty about when to seek medical care, resulting in a less critical selection of medical services to consume (Eichler, Wieser and Brügger, 2009). Similarly, poor communication and uncertainty around patient diagnosis may necessitate longer hospital stays and more diagnostic tests, even after controlling for the severity of illness (Hampers et al., 1999; John-Baptiste et al., 2004). Finally, it is possible that parents turn to doctors as trusted members of the community for general information or advice, especially if doctor visits are free at the point of service and the parent has a limited social network.

\footnotetext{
${ }^{1}$ One study by Aoki and Santiago (2018) examined the effect of language skills on children's birthweight (a marker of child health) and found no significant effect.
} 


\section{Data}

For our analysis we combine two main datasets: the Longitudinal Study of Australian Children (LSAC) survey and Medicare administrative records. We describe these two data sources below. We also use data from other sources in some analyses, including a measure of linguistic distance (from the Automated Similarity Judgment Program database) and Australian census information on the number of medical practitioners in the child's local area (see Appendix C for more detail).

\subsection{The Longitudinal Study of Australian Children}

Child and parent information come from the LSAC, an ongoing representative panel survey, that began in 2004. LSAC includes two cohorts: Cohort B (infants aged 0-1 in wave 1) and Cohort K (children aged 4-5 in wave 1). ${ }^{2}$ Essentially, children within randomly selected postcodes (stratified by geographical area) in the required age cohort were selected randomly from a Medicare enrolment database. Only one child per family was eligible for inclusion in the sample. Data on the health, behaviours and wellbeing of the child and on their parents' social and economic background (such as education, country of birth, first language spoken, year of immigration, parenting practices and sources of support) were collected through a face-to face interview with the child's primary parent.

The interviewer recorded observations about the English proficiency of the primary parent. ${ }^{3}$ Interviewers were asked: "How well do you consider [respondent] speaks English?", and could answer: Very well; Well; Not well; and Not at all. A parent is coded as having limited English proficiency (LEP) if their spoken English is rated 'Not well' or 'Not at all'. In our sample, $10 \%$ primary parents have LEP.

This study focuses on data from the first wave interview (2004) of 2,348 children from both cohorts whose primary parent is an immigrant. We link this data to Medicare records over a 10-year period (2004 to 2013), during which time the children in Cohort B were aged 0-10 and those in Cohort K were aged 4-14. We exclude 167 children who were born overseas and a further 6 children whose primary parent is not a biological mother or father. Our main estimation sample consists of 1,942 children born in Australia to an immigrant primary parent. ${ }^{4}$

\subsection{Administrative Medicare Records}

Medicare provides free or subsidised health care to all Australian citizens and permanent residents. The LSAC survey provides linked individual Medicare records from 2004 onwards. These records include

\footnotetext{
${ }^{2}$ For a detailed description of the study design, see Soloff, Lawrence and Johnstone (2005).

${ }^{3}$ In $97.4 \%$ of cases, this is the mother. We focus on the language skills of the primary parent because this is where we expect to see the largest intergenerational effect on health outcomes; the primary parent is more likely to make decisions around the child's health investments and health care utilisation. The English proficiency of the second parent is rated by the primary parent (not the interviewer), and we use this information in supplementary models.

${ }^{4}$ We exclude 3 children whose parents did not indicate their country of origin and 31 who did not provide age at arrival (both used to construct the instrumental variable). We also exclude 1 child with outlier health care costs $(>\$ 40,000)$. In robustness analyses, we show that the exclusion of these children has no impact on our results (see Appendix Table B1).
} 


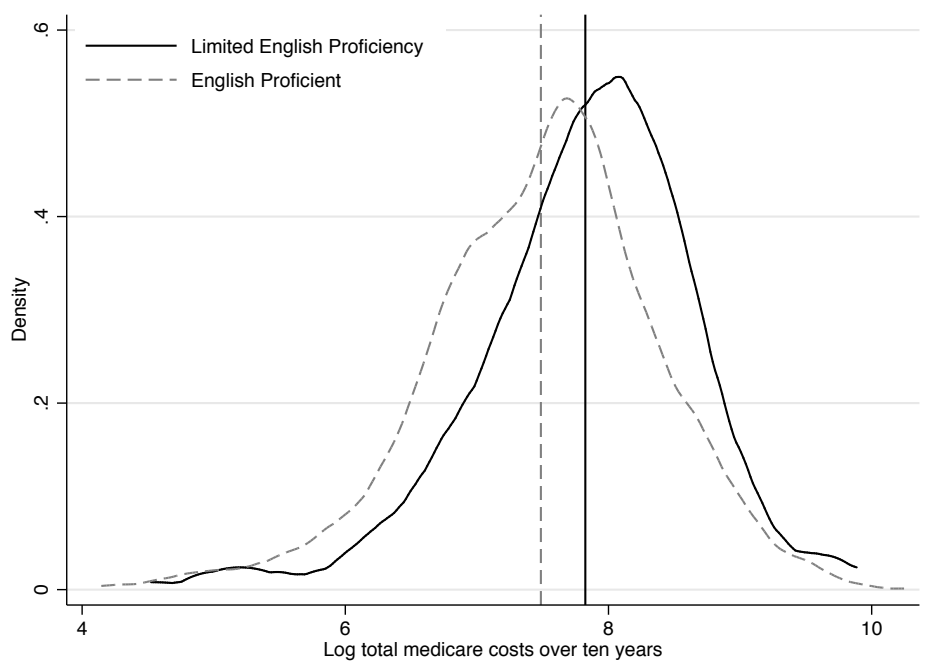

Figure 1: DENSITY PLOT OF CHILDREN'S LOG TOTAL MEDiCARE COSTS BY PARENT'S LANGUAGE PROFICIENCY

Note: The Figure plots children's log costs (adjusted to 2015 AUD) differentiated by the parents language ability. The mean among children of parents with LEP is $7.82(\mathrm{SD} 0.83, \mathrm{~N}=199)$ and 7.49 (SD 0.9, N=1,743) of those that are EP. Source: LSAC 2004-2016, own calculations.

all medical services funded under the Medicare Benefits Schedule (MBS) and pharmaceutical subsidies funded under the Pharmaceutical Benefits Scheme (PBS). Importantly, we have the cost incurred by Medicare for each MBS service and PBS subsidy (known as the "benefit" paid). This allows us to measure health care utilisation in terms of costs to the public health system. ${ }^{5}$ Moreover, the benefit amount is the same for the same service provided anywhere in Australia. Health practitioners can choose to charge exactly the benefit amount (known as bulk billing) and have patients pay nothing at the point of service. When physicians instead choose to charge a fee above the benefit amount, patients will pay the difference. We cannot observe this co-payment amount, but for most services it is a very small amount relative to the Medicare-funded component. ${ }^{6}$

Our main measure of interest is the total Medicare cost, calculated by adding MBS and PBS costs for each child over the 10-year period from 2004-2013 (inclusive). ${ }^{7}$ More specifically, we use

$$
y_{i}=\log \left(\sum_{t=1}^{10} \operatorname{costs}_{i t}\right) .
$$

\footnotetext{
${ }^{5}$ Services covered under the MBS include (but are not limited to) consultations by general practitioners (GPs) and specialists, diagnostic and imaging, pathology, dental services and some allied health services (including psychologists and speech pathologists). The MBS also covers hospital service records that are provided in private hospitals. However, because public hospital costs are not included in MBS records, we exclude all hospital services from this study. Public hospital records are held separately by states and territories. To provide some understanding of the relationship between parental LEP and hospital service use, we use parent reported information on hospital visits (see Section 5.2).

${ }^{6}$ Across all MBS services nationwide, about $80 \%$ are bulk billed (Medicare, 2017). The bulk-billing rate is even higher for children due to additional payment incentives (given to doctors) for GP, pathology and diagnostic services provided to children under 16. Bulk billing incentive payments are also financed through the MBS and are included in our total MBS costs. The co-payment amount is considerably lower for families with a health care card (HCC), a government concession card held by low-income families. In robustness models, we control for HCC status and examine heterogeneity of our main results by $\mathrm{HCC}$ status.

${ }^{7}$ The PBS provides a subsidy for eligible prescription drugs for most medical conditions (excluding over-the-counter medicines and in-hospital prescription drugs). The PBS subsidy paid by Medicare equals the difference between a fixed patient co-payment and the listed drug price (which are both indexed annually and applied nationwide).
} 
All costs are adjusted to 2015 AUD. ${ }^{8}$ Figure 1 shows the density of this measure of the child's health care between 2004 and 2013 by whether or not the primary parent has LEP. It shows that the distribution of costs is shifted to the right (higher costs) when language proficiency is limited. Over this 10-year period, the mean cost when parents have LEP is $\$ 3,382$; that is about $\$ 845(33 \%)$ higher than when parents speak English well or very well (see Appendix Table A1).

\section{Empirical Strategy}

\subsection{Model of child's health care utilisation}

The aim of this study is to examine the robustness of this association and the credibility of a causal interpretation. To address this question, we estimate models of the from

$$
y_{i_{a o}}=\alpha+\tau \operatorname{LEP}_{i_{a o}}+x_{i}^{\prime} \beta+\delta_{i_{a}}+\delta_{i_{o}}+\varepsilon_{i_{a o}},
$$

where for simplicity we denote the parent-child pair $i$, which depends on the parent's country of origin $o$, and her age at arrival $a . y_{i}$ represents the various outcomes we consider (mainly health care costs of the children), $\alpha$ denotes the intercept, $\tau$ our coefficient of interest, $x_{i}$ a varying set of covariates and $\beta$ its corresponding coefficient vector. Our set of basic controls $\left(x_{i}\right)$ include child characteristics: age in months, sex and cohort; and, parental characteristics: age in years, sex, decade of arrival into the host country (included flexibly as dummy variables); $\varepsilon_{i_{a o}}$ is an error term.

One key control variable is the parent's age at arrival into the host country. While language proficiency is influenced by earlier ages at arrival into the host country (see, for example, Lemmermann and Riphahn, 2018; Van den Berg et al., 2014; Van Ours and Veenman, 2006), it is also true that other non-language determinants of health investments (such as cultural assimilation and health system knowledge) are influenced by earlier arrival ages. By controlling for age at arrival, we control for these important nonlanguage effects on the child's health. Cultural background is another key characteristic of parents that may be related to both their LEP and their parenting or health practices. To account for this, we include the parent's country of birth (COB). This allows us to control for differences in country-specific factors, such as the health or educational system, cultural or genetic distances, prosperity, official languages, political freedom and culture of the country of origin. More specifically, we include both age at arrival and $\mathrm{COB}$ to allow for arbitrary non-language influences, through a fully-flexible specification including the full-set of fixed effects $\delta_{i_{a}}$ and $\delta_{i_{o}}$. As we will see below, after accounting for these and exploiting numerous identification strategies, we find little remaining evidence for selection on observables or unobservables.

\footnotetext{
${ }^{8}$ Parental consent to link Medicare records to LSAC children was obtained for $97 \%$ of all children in Wave 1 . Linkage was successful for $93 \%$ of children. All but one child incurred positive Medicare costs over the 10-year period. A majority $(85 \%)$ of Medicare expenses are through the MBS in our data. In the Appendix Table B1 we show that Medicare linkage does not differ by parental LEP.
} 
Our preferred specification includes the basic controls, age at arrival, and COB fixed effects. In our model, the coefficient on LEP reveals the causal effect of limited language skills on children's health care utilisation, under the important assumption that language skills are not correlated with the error term. One important potential threat to this assumption is that there may be other factors (such as parent's educational level, income, ability or motivation to learn) that are correlated with both parental LEP and children's health care utilisation, and their omission may lead to omitted variable bias. Our basic set of control variables only includes arguably exogenous variables. In the following sections, we describe our approach for determining the likely extent of omitted variable bias from observed (yet endogenous) and unobserved characteristics.

\subsection{Selection on observed characteristics}

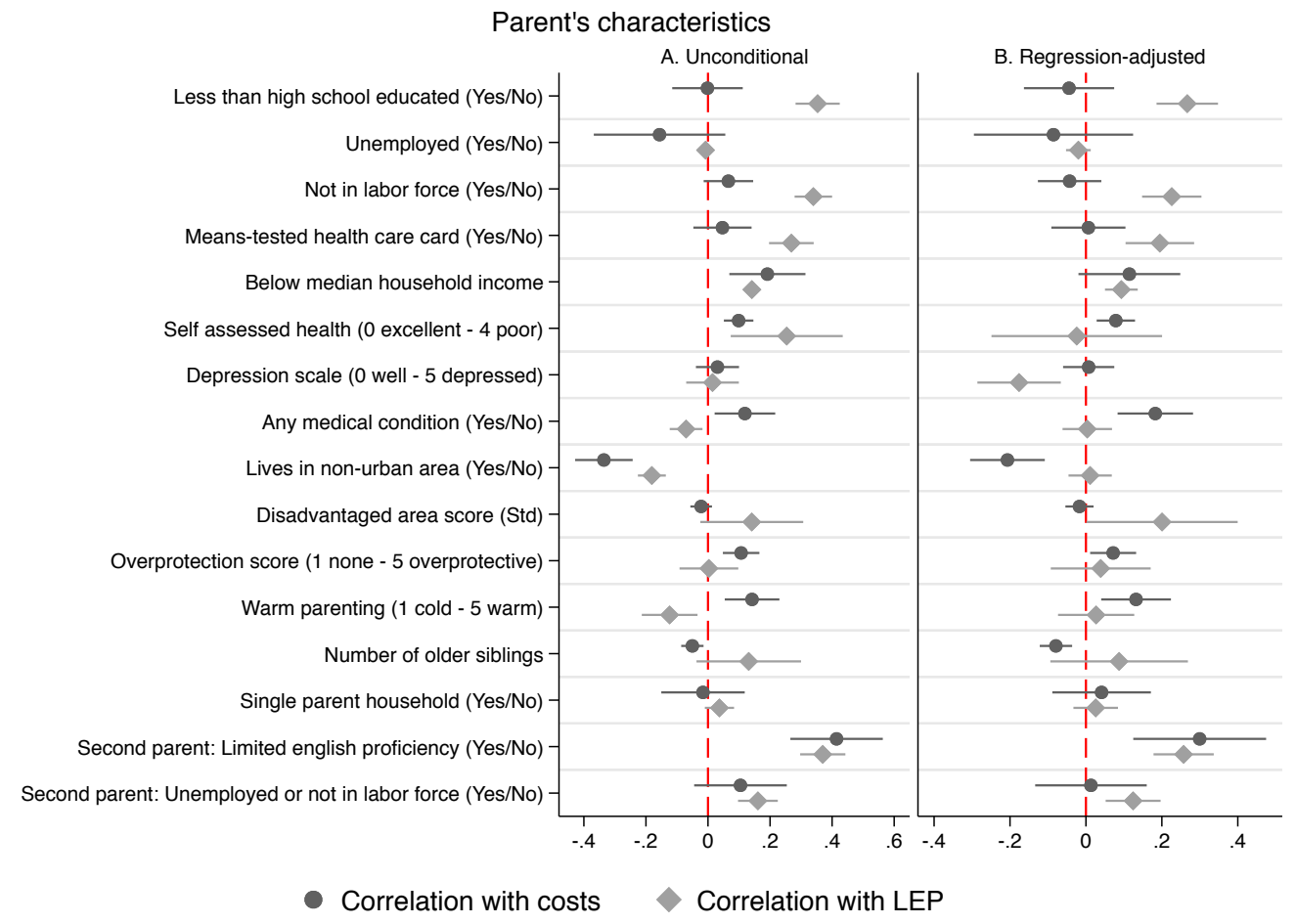

Figure 2: Compositional difFerences BetWeEn LEP AND EP PARENTS (GRAY), AND ASSOCIATIONS OF PARENT'S COSTS AND CHARACTERISTICS (BLACK), RAW LEFT AND CONDITIONAL RIGHT

Note: The Figure plots, descriptive regression coefficients (and $95 \%$ confidence intervals based on robust standard errors) between the log of children's health care costs and parents characteristics (black) and parents' English proficiency and characteristics (grey). Left graph raw differences between populations, right conditional on basic covariates (age, gender of both parent and child, LSAC-cohort) and decade, age at arrival, and country of birth fixed effects, regression coefficients are presented in Tables A2 (raw). Second parent's characteristics are based on a smaller subset of two-person households $(\mathrm{N}=1,772)$.

Source: LSAC (2004-2016), own calculations.

Parental characteristics, such as educational attainment or income (which can be affected by LEP and thus endogenous), may affect both opportunities for parents to learn English and children's health care use. The key question is, are there remaining compositional differences between parents who have LEP and those that do not, after accounting for our main set of control variables? Note, for an omitted 
variable bias to inflate the LEP effect in eq.(1), it must be true in the auxiliary model:

$$
\mathrm{LEP}_{i_{a o}}=\gamma_{0}+x_{i}^{\prime} \gamma+\gamma_{i_{a}}+\gamma_{i_{o}}+u_{i_{a o}},
$$

that parent's characteristics are (significantly) correlated with our variable of interest in the same direction as with the outcome, i.e. either

$$
\gamma_{\text {omitted }}>0 \quad \& \quad \beta_{\text {omitted }}>0 \quad \text { or } \quad \gamma_{\text {omitted }}<0 \quad \& \quad \beta_{\text {omitted }}<0 .
$$

We take advantage of the rich structure of the LSAC survey, which allows us to assess compositional differences in detail. In the graph on the left of Figure 2, we plot the unconditional raw correlations (the coefficient estimates and standard errors can be found in Appendix Table A2). In this visualisation of our balance testing procedure, it must be true that both dots and diamonds are on the same side, and statistically significant. The black dots show the raw differences in health care costs. The grey diamonds depict the raw correlation with LEP (i.e., eq.(2)). Correlations across the different variables are in the expected directions. For example, parents with less than high school education are positively associated with LEP, and parents with medical conditions have children with greater health care needs.

It is reassuring that very few variables indicate a potential for an omitted variable bias. Only four characteristics (below median household income, worse self-assessed health, living in urban areas, and the second parent having LEP) are significantly associated with both more health care utilisation and LEP. In the graph on the right of Figure 2, we adjust for our basic controls, most importantly age at arrival and COB fixed effects. Now, all differences are statistically insignificant and mostly in opposing directions. The only exception is the second parent having LEP. We do not treat this as selection in the traditional sense because the primary parent's language skills can be considered an indicator of the language proficiency of the household or of joint parental language proficiency. In robustness models we check the influence of the second parent's LEP (see Appendix B). Although insignificant, low household income may indicate a mild compositional difference, and we return to this in our analysis of possible mechanisms (see section 5.4).

Based on these tests, the LEP and non-LEP populations seem remarkably balanced. This suggests that our main OLS estimates are unlikely to suffer (substanitally) from omitted variable bias. We complement this evidence with a test of coefficient-stability (after including all additional covariates in the model) and provide estimates from bounding analyses, based on Altonji, Elder and Taber $(2005 a, b, 2008)$ and Oster (2017). We further provide extensive robustness analyses of our main OLS results.

\subsection{Instrumental variables approach}

Although reassuring, there is no guarantee that the lack of selection on observables (conditional on our set of controls) implies that there is no selection on unobservables. Moreover, the language proficiency of 


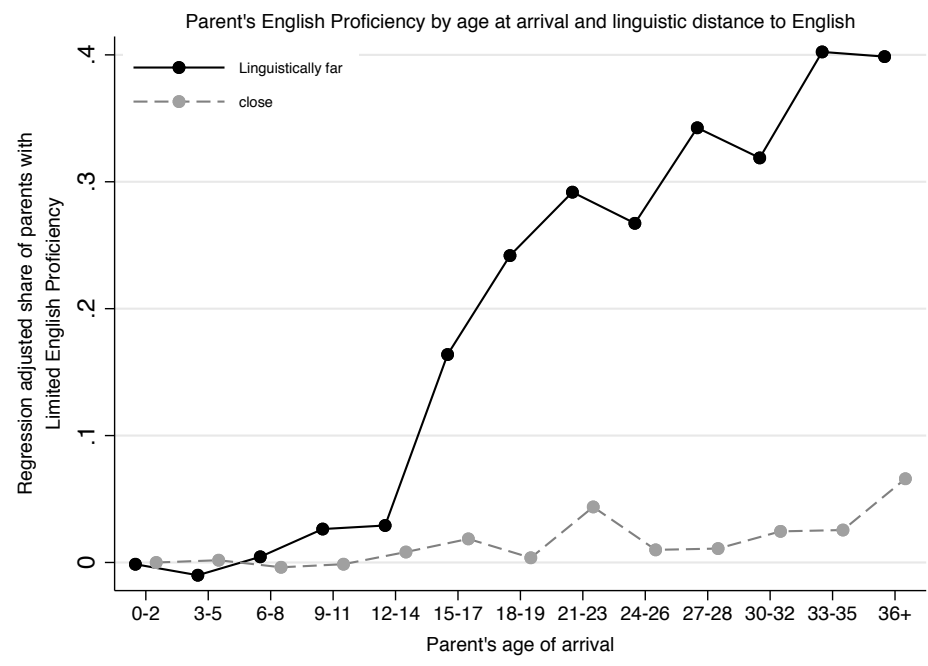

Figure 3: COMPARISON OF LEP BY AGE AT ARRIVAL OF PARENT AND LINGUISTIC DISTANCE TO ENGLISH

Note: The Figure plots first stage regression analogues. Linear probability model estimates of Limited English Proficiency on age at arrival (3-year grouped) indicators separately by country of births main language distance to English if larger than 0.8 (in the regressions we use the non-discretised measure) and if parents first language is not English (conditional on baseline controls: gender, age, LSAC-cohort), more information about variable construction and robustness to the linguistic distance measure can be found in the Appendix Figure B1.

Source: LSAC (2004-2016), ASJP v18, own calculations.

the parent may not be measured accurately, given that the rating is given by the interviewer. Arguably, interviewer-reported language proficiency is more objective than self-reported language proficiency, however it is still possible for it to be measured imprecisely.

To address these remaining omitted variable and measurement error concerns, we employ an IV approach, using the age at arrival into Australia to construct an instrument for parental language skills. Our approach is based on the 'critical period hypothesis' of language acquisition (Bleakley and Chin, 2004; Lenneberg, 1967) which proposes that it is less costly for a person to learn a language if they are exposed to it within the 'critical period' (i.e. childhood). This implies that among parents who were born in non-English-speaking countries, those who arrived in Australia during the 'critical period' are more likely to have better English language skills than those who arrived after this period, ceteris paribus.

Importantly, parents who arrive earlier may differ from later-arrivers in non-language ways as well. For example, they may be better assimilated into the Australian culture and more familiar with Australian institutions. This may influence their health investments and health care seeking behaviour, thereby violating the exogeneity assumption of the instrument. To address this issue, we use immigrants from English-speaking countries to control for any non-language effects of age at arrival. The age of arrival into Australia would not affect the language skills of parents who were born in English-speaking countries, because they were exposed to English prior to immigration. This essentially embodies a difference-indifference approach. 
To illustrate, suppose there were four immigrants to Australia: two from Papua New Guinea (PNG, English speaking country), one who came at age 6 and the other at age 16, and two from Vietnam (non-English speaking country) with parallel ages of arrival. Any difference in the health care use of the PNG immigrants' children could be attributed to age at arrival effects. For the Vietnamese immigrants, they would experience all of these effects in addition to having much less exposure to English prior to immigrating. Therefore, any difference between the Vietnamese immigrants (the 'treated') beyond the differences between the PNG immigrants (the 'control)' arguably can be attributed to language effects. These effects are the reduced English language skills that arise from the additional cost of acquiring a second language when arriving into Australia at a later age (for further discussion, see Bleakley and Chin, 2004, p481).

It is possible that within a non-English-speaking country, there is heterogeneity in how similar the native language is to English (for example, Dutch is more similar to English than Vietnamese), and that this similarity or closeness to English plays a key role in the ease of adopting English as a second language. Clarke and Isphording (2017) make use of the variation in distances of languages to English, rather than using the discrete change from non-English to English COB. The idea is that the further away an individual's native language environment is to English, the more costly it is to acquire English language skills (for details see Appendix C).

Figure 3 illustrates the strong relationship in our data between the parent's age at arrival in Australia and their language skills. In particular, if parents immigrated from linguistically far countries (solid black line), then there is a sharp rise in the probability of them having LEP if they arrived after around age 12. In contrast, parents who immigrated from linguistically close countries (dashed grey line) have a low probability of having limited language skills regardless of their age at arrival. This suggests that for immigrants from linguistically far countries, there is a 'critical period' of language acquisition which ends at age 12. This pattern is consistent with previous studies from the U.S. (e.g. Bleakley and Chin, 2004) and Australia (e.g. Guven and Islam, 2015). To reflect this relationship, we use a piecewise linear measure of age at arrival; it allows for a decline in language learning ability that starts at age 12 and grows linearly thereafter: $\max \left\{0, A A_{i_{a}}-11\right\}$, where $A A_{i_{a}}$ denotes the age at arrival of the parent. Our instrumental variable is then the interaction between this variable and the linguistic distance: $\max \left\{0, A A_{i_{a}}-11\right\} \times L D_{i_{o}}$ based on the parent's country of birth. This allows the difference in language proficiency between the parents from linguistically "far" countries and linguistically "close" countries to start growing at age 12. We augment eq. (2) using this IV - the first-stage regression using the discontinuous or piecewise-linear specification of the critical period, is:

$$
\operatorname{LEP}_{i_{a o}}=\gamma_{0}+\gamma_{z} \max \left\{0, A A_{i_{a}}-11\right\} \times L D_{i_{o}}+x_{i}^{\prime} \gamma+\gamma_{i_{a}}+\gamma_{i_{o}}+u_{i_{a o}}
$$


Other studies have suggested that the critical period of language acquisition ends at around age 9 (e.g. Dillender 2017 and Aoki and Santiago 2018). In robustness models we use age 9 as the cut-off of the critical period. We discuss several further robustness tests concerning this IV approach below, in Section 4.4 and Appendix B.

\section{Results}

\subsection{The relationship between parental language skills and children's health care utilisation}

Table 1: Association of immigrant parent's language SKILls And CHILDREN'S HEALTH CARE UTILISATION, OLS REGRESSIONS

\begin{tabular}{|c|c|c|c|c|c|c|c|c|}
\hline \multicolumn{9}{|c|}{ Dependent variable: Log total Medicare costs (in 2015 AUD) } \\
\hline & \multicolumn{6}{|c|}{ Coefficient stability } & \multicolumn{2}{|c|}{ AET-Bounds } \\
\hline & $(1)$ & $(2)$ & $(3)$ & $(4)$ & $(5)$ & $(6)$ & $(7)$ & $(8)$ \\
\hline LEP & $\begin{array}{c}0.338 \\
(0.063)\end{array}$ & $\begin{array}{c}0.347 \\
(0.065)\end{array}$ & $\begin{array}{c}0.329 \\
(0.066)\end{array}$ & $\begin{array}{c}0.253 \\
(0.077)\end{array}$ & $\begin{array}{c}0.229 \\
(0.076)\end{array}$ & $\begin{array}{c}0.219 \\
(0.082)\end{array}$ & $\begin{array}{c}0.215 \\
(0.081)\end{array}$ & $\begin{array}{c}0.176 \\
(0.081)\end{array}$ \\
\hline Selection on observables & & & & & & & $50 \%$ & $100 \%$ \\
\hline$N$ & 1,942 & 1,942 & 1,942 & 1,942 & 1,942 & 1,942 & 1,942 & 1,942 \\
\hline $\mathrm{R}^{2}$ & 0.013 & 0.068 & 0.088 & 0.205 & 0.177 & 0.210 & & \\
\hline $\operatorname{adj} R^{2}$ & 0.013 & 0.064 & 0.063 & 0.097 & 0.103 & 0.099 & & \\
\hline Basic covariates & & $\checkmark$ & $\checkmark$ & $\checkmark$ & $\checkmark$ & $\checkmark$ & $\checkmark$ & $\checkmark$ \\
\hline Age at arrival FE & & & $\checkmark$ & $\checkmark$ & $\checkmark$ & $\checkmark$ & $\checkmark$ & $\checkmark$ \\
\hline Cob FE & & & & $\checkmark$ & & $\checkmark$ & $\checkmark$ & $\checkmark$ \\
\hline Language FE & & & & & $\checkmark$ & & & \\
\hline Other covariates & & & & & & $\checkmark$ & & \\
\hline
\end{tabular}

Notes: Table presents OLS coefficients and robust standard errors in brackets. Columns (1) - (6), present coefficient stability analysis: (1) raw difference; (2) including basic covariates (parent's sex, age and age and sex of the child, as before) and decade of arrival fixed effects; (3) adds age at arrival fixed effects; (4) adds county of birth fixed effects; (5) adds instead first language spoken fixed effects; (6) includes all (potentially endogenous) covariates from Figure 2 and state fixed effects as well as 1-digit occupation fixed effects. Columns (7) and (8) provide Altonji-Elder-Taber-style bounds, as we have a continuous outcome variable and a binary endogenous regressor we use an inverse mills ratio setup, to construct the bounds. The first stage is estimated using the bias reduced probit estimator discussed in Kunz, Staub and Winkelmann (2017), due to the presence of perfect prediction, column (6) sets the correlation to half the implied selection on observables for model (4) and Column (8) presents the implied estimate under the assumption that selection on observables is equal to the selection on unobservables. Selection on observables is estimated to be 0.051 . Further the linearised Oster bounds are even larger (50\% - $0.235,100 \%-0.211$ : make it equal to 0 is roughly 0.17 , ie. three times as large). More details on the variables used and other variables in the model are presented in the Appendix Table A1 and detailed bounding results in Table B2.

Source: LSAC (2004-2016), own calculations.

Table 1 shows the OLS regression coefficient estimates for $\tau$ in eq.(1), with control variables added in a stepwise fashion. As discussed above, column (1) shows that children incur about 33\% more Medicare costs over a 10-year period (2004-2013) if their primary parent has LEP, compared with having a parent who is proficient in English $(p<0.01)$. This corresponds to a difference of, roughly, \$845 AUD (see Appendix Table A1), which is sizeable in terms of health care costs. There may be several reasons for this difference, such as a shorter time to assimilate or older parents, however, this relationship changes little when basic covariates, decade of arrival and age at arrival are included (column 2).

Even when country of birth (COB) differences are controlled for through COB fixed effects in column 
(4), LEP is associated with Medicare costs that are about $25 \%$ higher $(p<0.01)$. This amounts to about $\$ 600$ over the 10 year period (see Appendix B1, where we present this regression using costs in AUD). This economically large and statistically significant difference appears to be very stable; it matters little whether we exchange COB for first language fixed effects (column 5), or add other covariates (such as parent's education, occupation, income and health status) (column 6). This confirms the balance test results discussed in the previous section.

In the Appendix Table B1 we provide several specification tests. We use 5 nearest neighbour matching and kernel matching, which are less dependent on functional form than the OLS estimates, and we restrict the OLS to the common support (implied by a propensity score regression, analogues to eq.(2), see also discussion in footnote 10) to assure comparability between LEP and non-LEP parents. We use dollar costs (raw scale) in OLS, Poisson and Gamma regressions to account (more appropriately) for the nonlinear function of health care costs (discussed by, for example Manning, 1998; Basu and Manning, 2009; Jones, 2000; Buntin and Zaslavsky, 2004; Cantoni and Ronchetti, 2001). We also show that the results are robust to: controlling for both parents having LEP; separately controlling for whether the primary parent speaks English "not at all"; and, including the parenting style (warm or overprotective) as covariates. $^{9}$

\subsection{Testing for selection on unobserved characteristics}

Figure 2 indicated little compositional differences between the parents, and the stability of the coefficient in Table 1 is reassuring, especially as the $\mathrm{R}^{2}$ increases substantially by the inclusion of covariates (Oster, 2017). To further understand the extent of the omitted variable problem, we perform a bounds analysis. Following Altonji, Elder and Taber (2005a,b, 2008) and Oster (2017), we demonstrate the robustness of our OLS estimates to selection on unobservable characteristics, assuming that the selection on observable characteristics is informative about the bias arising from unobservables. The main purpose of this analysis is to support the credibility of the OLS results in identifying a causal effect of language skills on children's health outcomes, rather than as a formal test of a selection.

In sum, our bounding analysis provides further evidence that our conditional OLS estimates are unlikely to suffer from a sizeable selection on unobserved characteristics. As shown in Table 1, the main estimates are highly robust to scenarios in which the selection on unobservables is equal to $50 \%$ of the selection on observables (column 7) and $100 \%$ of the selection on observables (column 8). The coefficients for having LEP are $0.215(p<0.05)$ and $0.176(p<0.05)$ respectively. ${ }^{10}$ Additionally, we find that for the selection

\footnotetext{
${ }^{9}$ In additional sensitivity analyses, we i) drop all observations with missing covariates; ii) include all children born overseas and whose main care giver is a grandparent; iii) drop all small countries (with too few observations to be used effectively); iv) cluster small countries; v) include controls for postcode and larger area fixed-effects. Further, we show that successful linkage of Medicare records is slightly higher among LEP parents, and that this difference is not statistically significant.

10 As detailed further in the appendix, akin to the Altonji, Elder and Taber approach we use a generalised roy-selection model (Heckman, 1976; Lee, 1978), consistent with our variables: OLS second stage and binary-Probit first stage. Due to the large number of fixed effects, there are many perfect prediction cases, due to these we use the bias-reduced probit
} 
on unobservables to wipe out the estimated LEP effect completely (to zero), it would need to be three times as large as the selection on observables. Based on the findings presented so far, we cannot find evidence that the selection on unobservables matters much in this application, at least if the selection on observables is a useful guide to the selection on unobservables.

\subsection{IV estimates of the effect of parental language skills on children's health care utilisation}

Table 2: Instrumental VARIABLE REgRESSIONS USING CRITICAL PERIOD HYPOTHESIS

\begin{tabular}{|c|c|c|c|c|c|c|}
\hline \multicolumn{7}{|c|}{ Dependent variable: Log total Medicare costs (in 2015 AUD) } \\
\hline & Main & $\begin{array}{l}\text { Bleakly-Chin } \\
1[C o b=E n g]\end{array}$ & $\begin{array}{l}\text { Dillinder } \\
\text { Age } 9\end{array}$ & $\begin{array}{l}\text { Extended } \\
\text { Covariate } \\
\text { Set }\end{array}$ & $\begin{array}{c}\text { First } \\
\text { Langauge } \\
\text { Fixed Effects }\end{array}$ & $\begin{array}{c}L D_{i o} \\
\text { based on } \\
\text { Language }\end{array}$ \\
\hline & (1) & $(2)$ & $(3)$ & (4) & $(5)$ & $(6)$ \\
\hline \multicolumn{7}{|l|}{ OLS: } \\
\hline LEP & $\begin{array}{c}0.253 \\
(0.077)\end{array}$ & $\begin{array}{c}0.253 \\
(0.077)\end{array}$ & $\begin{array}{c}0.253 \\
(0.077)\end{array}$ & $\begin{array}{c}0.219 \\
(0.082)\end{array}$ & $\begin{array}{c}0.229 \\
(0.076)\end{array}$ & $\begin{array}{c}0.237 \\
(0.077)\end{array}$ \\
\hline \multicolumn{7}{|l|}{ IV: } \\
\hline LEP & $\begin{array}{c}0.905 \\
(0.351)\end{array}$ & $\begin{array}{c}0.882 \\
(0.386)\end{array}$ & $\begin{array}{c}0.828 \\
(0.361)\end{array}$ & $\begin{array}{c}0.990 \\
(0.436)\end{array}$ & $\begin{array}{c}0.713 \\
(0.335)\end{array}$ & $\begin{array}{c}0.922 \\
(0.422)\end{array}$ \\
\hline $\begin{array}{c}\mathrm{H}_{0}: \mathrm{OLS}=\mathrm{IV} \\
\text { p-value }\end{array}$ & 0.050 & 0.088 & 0.094 & 0.063 & 0.134 & 0.093 \\
\hline $\begin{array}{l}\mathrm{RF}: \\
\quad \max \{0, A A-11\} \times L D\end{array}$ & $\begin{array}{c}0.015 \\
(0.006)\end{array}$ & $\begin{array}{c}0.013 \\
(0.006)\end{array}$ & $\begin{array}{c}0.013 \\
(0.006)\end{array}$ & $\begin{array}{c}0.013 \\
(0.006)\end{array}$ & $\begin{array}{c}0.012 \\
(0.006)\end{array}$ & $\begin{array}{c}0.014 \\
(0.006)\end{array}$ \\
\hline $\begin{array}{l}\text { FS: } \\
\quad \max \{0, A A-11\} \times L D\end{array}$ & $\begin{array}{c}0.017 \\
(0.002)\end{array}$ & $\begin{array}{c}0.015 \\
(0.002)\end{array}$ & $\begin{array}{c}0.015 \\
(0.002)\end{array}$ & $\begin{array}{c}0.014 \\
(0.002)\end{array}$ & $\begin{array}{c}0.017 \\
(0.002)\end{array}$ & $\begin{array}{c}0.015 \\
(0.002)\end{array}$ \\
\hline Fstat & 76.45 & 70.21 & 78.40 & 54.55 & 75.46 & 77.86 \\
\hline$N$ & 1,942 & 1,942 & 1,942 & 1,942 & 1,942 & 1,908 \\
\hline Basic covariates & $\checkmark$ & $\checkmark$ & $\checkmark$ & $\checkmark$ & $\checkmark$ & $\checkmark$ \\
\hline Age at arrival FE & $\checkmark$ & $\checkmark$ & $\checkmark$ & $\checkmark$ & $\checkmark$ & $\checkmark$ \\
\hline Cob FE & $\checkmark$ & $\checkmark$ & $\checkmark$ & $\checkmark$ & & \\
\hline $\begin{array}{l}\text { Other covariates } \\
\text { Language FE }\end{array}$ & & & & $\checkmark$ & $\checkmark$ & $\checkmark$ \\
\hline
\end{tabular}

Notes: Table present coefficient estimates of OLS regression, 2SLS, Reduced From [RF] and First stage [FS]. Column (1) corresponds to column (5) in Table 1 as a reference, see notes for variable descriptions. For the IV it uses linguistic distance based on COB, which is set to 0 if first language learned was English as in Clarke and Isphording (2017). Column (2) uses as IV the Bleakley and Chin (2004) specification, of a dummy for English speaking CoB instead of $L D$, column (3) the Dillender (2017) specification using as Age cutoff 9 years, i.e. $\max \{0, A A-8\} \times L D$, column (4) adds all potentially endogenous covariates to the main model, and (5) replaces country of birth fixed effects with first-language fixed effects, finally column (6) uses linguistic distance based on the first language spoken instead of COB official language as $L D$.

Source: LSAC (2004-2016), own calculations.

To address any remaining concerns about selection on unobservables and potential measurement error, we turn to our IV estimates that use discontinuity at the 'critical period' to identify the effect of LEP. In Table 2, we present these IV estimates (and corresponding OLS estimates) under various specifications. Also

fixed effects model developed in Kunz, Staub and Winkelmann (2017) based on an estimator derived by Kosmidis and Firth (2009). It is reassuring that we get even larger point estimates when we use Oster's approach that does not rely on a nonlinear first stage nor does it suffer from perfect prediction. The full results are presented in Appendix Table B2. 
shown are the reduced-form and first-stage estimates for each specification. In all models, we include the full set of controls (including age at arrival and COB fixed effects). Our preferred specification estimates, using the ASJP linguistic distance and discontinuity at age 12 arrival, are shown in column (1). These suggest that a parent's LEP has a significant and positive effect on health care costs incurred by the child, by about $90 \%$. This is about 3.5 times the size of the OLS effect (25\%). In terms of magnitude, it amounts to about $\$ 2,280$ over the 10 -year period, or an average of $\$ 228$ extra per year, which is a sizeable but reasonable amount. The reduced-form estimates show that the IV has a positive and significant effect on health care costs, while the first-stage estimates demonstrate that the IV is a powerful predictor of having a language proficiency. The partial F-statistic of the instrument in the first stage equation is well beyond conventional rules of thumb. Although it is well known that the power of the Hausman test for equality between the OLS and IV estimates is limited, our results suggest that they are only weakly different $(p=0.05)$ and that there is limited evidence for a biased OLS coefficient. We interpret this to mean that there is mild evidence of some endogeneity in the OLS estimates (see Young, 2017, for a detailed discussion on these topics). Taken together, either the OLS or IV results suggest that there is an economically sizeable and statistically significant difference in utilisation of health care services by parents' language skills.

In columns (2) and (3), we replicate the specifications used in the literature based on the critical period hypothesis. Specifically, in column (2) we replace the continuous linguistic distance with a binary indicator for whether or not the COB is officially English-speaking (akin to the model used by Bleakley and Chin, 2004). In column (3) we change the critical period cut-off age from 12 to 9 (i.e., the same as in Dillender, 2017). In both of these specifications, the IV estimate is stable (between 0.83 and 0.88 ) and statistically significant. The test for equality between the OLS and IV estimates again suggests that they are only weakly different ( $p=0.09$ for both). When we include our extended set of covariates (such as education, income and occupation) in column (4), the IV estimate remains similarly large and significant (0.99). Here again the IV model is only weakly different from the OLS $(p=0.06)$. Further, we show that our main results are also robust to including the first language FE instead of COB FE (column 5), and using the parent's reported first language instead of their COB official language to calculate the linguistic difference (column 6). Overall, we show that our IV estimates are highly robust to various specifications. Given the weak difference between OLS and IV estimates, we interpret our IV estimates as an upper bound (and the OLS estimates as a lower bound) effect of parental LEP on health care costs incurred by children. This suggests that, if anything, there is a downward bias in the OLS estimates. It can be rationalised by measurement error (see for example, Clarke and Isphording, 2017; Bleakley and Chin, 2004). Alternatively, it could be explained by an omitted variable bias that reduces the correlation towards zero (e.g. if lower parental cognitive ability were positively correlated with LEP and negatively with health services for their child). ${ }^{11}$

\footnotetext{
${ }^{11}$ We further explored the potential for heterogeneous treatment effects (based on unobservables) by estimating marginal treatment effect models. Although, we cannot reject the constant treatment effect assumption, this may be a result of our
} 


\subsection{Robustness of IV estimates}

We undertake extensive robustness tests which are shown in Appendix B. Briefly, we are concerned about two main issues in using this IV specification. First, our sample size precludes us from focusing exclusively on parents who themselves were childhood immigrants. Our primary concern is that adult immigrants select where and when to immigrate based on their expected returns, and this reasonably might differ by country of origin (note, a similar argument can be made for childhood immigrants if their parents try to maximise the returns for their offspring and immigrate when their children are younger). We run several tests to assess whether this is a cause for concern. First, we merge 2011 Census information on the year of migration and the country of birth of the parent to determine if the parent arrived in Australia in a "high migration wave." 12 The idea behind this is that if a country experiences a large shock (e.g. a civil war) resulting in a spike in international migration, then the immigrants from this country during this period are less able to choose when to immigrate. In other words, there is likely to be less selection by age at arrival among these immigrants. We find no evidence for heterogeneity in the main effect by parents who came in a high migration wave relative to those who came in other periods. Another way we test for selection among adult immigrants is by allowing for a more flexible first stage. Specifically, we include a second instrument that allows for a different slope for age at arrival after 18. And in another specification, we allow the first stage to be fully flexible with respect to age at arrival by interacting each age at arrival with linguistic distance. Although the F-statistic is small, our results from these additional tests are very similar to the main estimates.

Second, it might be the case that linguistic distance captures other differences between countries (e.g. differences in economic situation, cultural distance, or health systems). Because we control for COB fixed effects, we are able to remove all country-specific characteristics that do not vary with age at arrival. However, linguistic distance may be capturing something else that differs by age at arrival. For example, there might be differences in the quality of the education system between linguistically far and close speaking countries, and this could independently influence the parenting behaviours of younger versus older arrivers. We address this concern first by examining heterogeneity in our main estimates by COB characteristics (above average GDP, Commonwealth, free and universal health care system). We find no significant difference in the LEP effect, although the effect of LEP on child's health care utilisation is slightly larger for immigrants from free and universal health care systems, Commonwealth countries, and below average (in-sample) GDP countries. As an additional test, we include as control variables, the interaction between parent's age at arrival and each of the following COB characteristics: GDP; expenditure on health (\% GDP); expenditure on education (\% GDP); and, genetic distance (based on Spolaore and Wacziarg, 2009). These interaction terms allow country-specific characteristics to vary by

\footnotetext{
limited sample size.

${ }^{12} \mathrm{~A}$ parent is classified as arriving in a high migration wave if the number of immigrants from their COB in the year they migrated was 1.5 times larger than the average number of migrants from this country. Appendix Figure B2 illustrates migration waves for the six main countries of origin: China, Vietnam, Lebanon, Philippines, India and South Africa.
} 
age at arrival. Thus they capture, for example, the differential effects of COB educational systems on parenting behaviours of early and later arrivers. The LEP effect remains robust to the inclusion of these additional variables. In summary, none of our robustness tests indicate that our IV might be invalid.

\section{$5 \quad$ Heterogeneity and mechanisms}

So far, our results taken together indicate that there is an economically significant relationship between parents' language skills and their children's health care utilisation. In the following section we assess heterogeneity and test several hypotheses that might explain this relationship.

\subsection{How does the effect vary by the child's age?}

The average annual Medicare cost for all children is considerably higher for younger children, especially in the first couple of years of life (see Appendix Figure A1, left panel). These costs appear to be significantly greater for children of parents with LEP at each age up until age 10, after which the average costs of both groups are very close to zero. The right panel of the figure shows the heterogeneity in the OLS and IV estimates by the child's age. Although positive for all ages, the greatest effect of LEP on child's health care use (consistently significant for both OLS and IV models) occurs when children are between age 4 and 6 . This is the time when children typically are starting kindergarten and the first year of school. ${ }^{13}$

\subsection{Are they simply less healthy?}

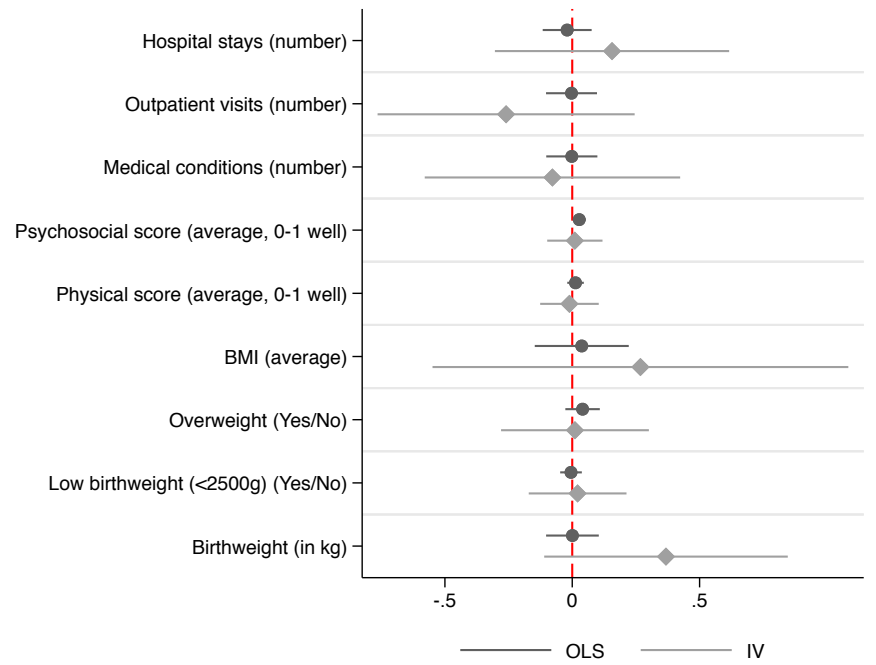

Figure 4: Effect of limited English proficiency on Child health outcomes, OLS AND IV

Note: The Figure plots regression coefficients (and 95\% confidence intervals based on robust standard errors) from OLS and IV regressions comparable to those in column (1) of Table 2, using various child health measures as dependent variables (explained in more detail in the Appendix Table C2 and the regression results in table form in Table A4).

Source: LSAC (2004-2016), own calculations.

\footnotetext{
${ }^{13}$ These results should be interpreted with care as the sample size is considerably smaller (about half) before age 4 and after age 10. This is because children in our sample are followed over a 10 year period ranging from 0 to 10 (Birth cohort) and 4 to 14 (Kinder cohort). Therefore, the ages of the two cohorts overlap between ages 4 and 10 .
} 
Next, we explore the mechanisms behind the higher Medicare costs of children of parent's with LEP. Our first and primary concern is that these children are in poorer health and thus need more medical attention. We investigate this by examining the effect of parental language skills on various child health outcomes (over the 10-year period) using anthropometric and parent-reported measures collected in the LSAC (see Appendix Table A4 and C2 for details on each of the health measures). Figure 5 illustrates the OLS and IV regression coefficients of a parent with LEP. If children of parents with LEP have more serious health complications, we then might expect them to have more hospital visits. However, using parent-reported information on the number of years (over the 10-year period) the child had a hospital visit, we find no difference in the number of hospital visits (as either outpatients or inpatients) by parental LEP.

Next we examine whether the child had more health problems using three parent-reported measures: an indicator of whether the child has a long-term health condition or disability; an overall physical health score; and, an overall mental health score (both derived from the Pediatric Quality of Life instrument, PEDsQL). Our OLS and IV estimates confirm that none of these measures of child health differ significantly by parental LEP. To gain a more objective measure of health problems, we examine the child's body mass index (BMI) and an indicator for whether the child was overweight, ${ }^{14}$ according to interviewer-measured height and weight. We find no evidence of differences in these by parental LEP.

One might argue that all of these health measures could have been influenced by more medical utilisation, and therefore our nil results may be due to the very fact that medical services have eliminated any differences in health problems. We therefore examine the child's birthweight as our final and arguably 'cleanest' measure of health, which cannot be affected by future health care utilisation. Low birthweight is a known strong predictor of later health complications (Hack, Klein and Taylor, 1995). We find that neither birthweight $(\mathrm{kg})$ nor an indicator for low birthweight $(<2500 \mathrm{~g})$ differ significantly by parental LEP. This is consistent with work of Aoki and Santiago (2018), who found no effect of parental LEP on birthweight. In summary, we find no evidence to suggest that children are sicker or at greater risk of health problems if their parents have LEP.

\subsection{What medical treatments are they using?}

Determining which Medicare treatments drive the higher costs is interesting in itself, but also may uncover possible mechanisms for this finding. We first split the Medicare costs into their two main components: MBS (medical services) and PBS (drug subsidies). We find that parental LEP has a positive and significant effect on both MBS and PBS costs. However, the effect is driven largely by MBS services (on average MBS costs are $91 \%$ of total costs is in our sample). Given this larger contribution of Medicare costs through the MBS, we break down MBS utilisation into five categories of services: (1)

\footnotetext{
${ }^{14}$ According to age- and gender-specific international BMI cut-points (Cole et al., 2007).
} 


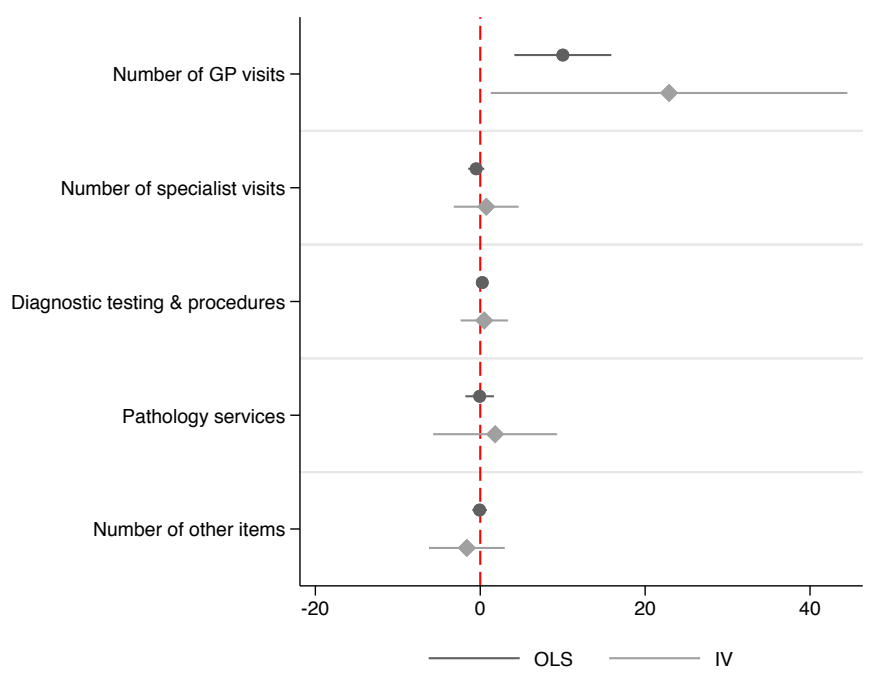

Figure 5: EfFect of Limited English Proficiency on MEdicAl SERVice items, OLS AND IV

Note: The Figure plots regression coefficients (and 95\% confidence intervals based on robust standard errors) from OLS and IV similar to Figure 4, using number of MBS (medical services) used as dependent variables(explained in more detail in the Appendix Table C2).

Source: LSAC (2004-2016), own calculations.

general practitioner (GP) visits; (2) specialist doctor visits; (3) diagnostic and imaging procedures; (4) pathology tests; and, (5) all other services. We then estimate the effect of parental LEP on the number of times the child used each of these services over the 10-year period (using both OLS and IV). ${ }^{15}$ The estimated coefficients (and their 95\% confidence intervals) are shown in Figure 5. There is a large and significant effect for GP visits (IV estimates suggest that parental LEP leads to 23 more GP visits over the 10-year period).

However, parental LEP does not appear to affect any other medical service other than GP visits. This tells us two important things. First, the literature suggests that there may be supply-side explanations for higher medical costs if physicians err on the side of caution by ordering more diagnostic tests when unable to rely on the patient's description of the health problem (Jacobs et al., 2006; Hampers et al., 1999). However, our insignificant effects for diagnostic and pathology services (all of which must be prescribed by the physician), suggest little evidence of over-servicing by physicians in Australia due to parental LEP. Second, the insignificant effect of LEP on specialist doctor visits again indicates that these children are not experiencing higher Medicare costs because of more serious or specialised health complications. It seems that these children are going to the GP more often for fairly common ailments.

\footnotetext{
${ }^{15}$ Several studies assess how to best model GP demand, especially if there is an excess amount of zeros: Pohlmeier and Ulrich (1995); Staub and Winkelmann (2013); Kunz and Winkelmann (2017). However, as almost all children in our sample have a positive use of medical services, excess zeros is less of a concern here.
} 


\subsection{Why are GP visits higher?}

Table 3: LEP on GP visits: Heterogeneity by SES, PARENTing AND COMmUnicAtion BARRIERs, OLS AND IV

\begin{tabular}{|c|c|c|c|c|c|c|c|c|c|}
\hline & \multirow[b]{3}{*}{ Base } & \multicolumn{3}{|c|}{ Socio-Economic Status } & \multicolumn{3}{|c|}{ Parenting style \& uncertainty } & \multirow{2}{*}{\multicolumn{2}{|c|}{$\frac{\text { Communication barriers }}{\text { Own language }}$}} \\
\hline & & \multirow{2}{*}{$\begin{array}{c}<\text { med } \\
\mathrm{HH} \text { income }\end{array}$} & \multirow{2}{*}{$\begin{array}{l}\text { Means- } \\
\text { tested HC }\end{array}$} & \multirow{2}{*}{$\begin{array}{l}\text { High } \\
\text { SEIFA }\end{array}$} & \multirow{2}{*}{$\begin{array}{c}\text { Over- } \\
\text { protective }\end{array}$} & \multirow[b]{2}{*}{ Warm } & \multirow{2}{*}{$\begin{array}{l}\text { No older } \\
\text { siblings }\end{array}$} & & \\
\hline & & & & & & & & GP & Teacher \\
\hline & (1) & $(2)$ & (3) & $(4)$ & $(5)$ & (6) & (7) & (8) & (9) \\
\hline \multicolumn{10}{|l|}{ OLS } \\
\hline $\mathrm{LEP} \times D$ & $\begin{array}{l}10.02 \\
(3.00)\end{array}$ & $\begin{array}{l}10.06 \\
(3.28)\end{array}$ & $\begin{array}{l}10.63 \\
(4.27)\end{array}$ & $\begin{array}{l}8.96 \\
(3.97)\end{array}$ & $\begin{array}{l}13.14 \\
(4.59)\end{array}$ & $\begin{array}{c}9.53 \\
(3.26)\end{array}$ & $\begin{array}{l}12.42 \\
(4.35)\end{array}$ & $\begin{array}{l}12.49 \\
(3.67)\end{array}$ & $\begin{array}{l}12.21 \\
(5.38)\end{array}$ \\
\hline $\mathrm{LEP} \times(1-D)$ & & $\begin{array}{c}9.82 \\
(5.85)\end{array}$ & $\begin{array}{l}9.50 \\
(3.71)\end{array}$ & $\begin{array}{l}11.04 \\
(4.05)\end{array}$ & $\begin{array}{c}8.13 \\
(3.58)\end{array}$ & $\begin{array}{l}11.42 \\
(6.02)\end{array}$ & $\begin{array}{c}8.90 \\
(3.63)\end{array}$ & $\begin{array}{c}4.31 \\
(4.82)\end{array}$ & $\begin{array}{c}7.64 \\
(3.59)\end{array}$ \\
\hline p-value $(D=1-D)$ & & 0.97 & 0.83 & 0.70 & 0.36 & 0.77 & 0.50 & 0.14 & 0.45 \\
\hline \multicolumn{10}{|l|}{ IV } \\
\hline $\mathrm{LEP} \times D$ & $\begin{array}{c}22.90 \\
(11.03)\end{array}$ & $\begin{array}{c}23.77 \\
(11.34)\end{array}$ & $\begin{array}{l}18.07 \\
(9.90)\end{array}$ & $\begin{array}{c}25.12 \\
(13.68)\end{array}$ & $\begin{array}{c}24.10 \\
(14.61)\end{array}$ & $\begin{array}{c}24.01 \\
(11.08)\end{array}$ & $\begin{array}{c}35.06 \\
(14.51)\end{array}$ & $\begin{array}{c}29.67 \\
(11.91)\end{array}$ & $\begin{array}{c}21.33 \\
(12.66)\end{array}$ \\
\hline $\operatorname{LEP} \times(1-D)$ & & $\begin{array}{c}18.84 \\
(12.92)\end{array}$ & $\begin{array}{c}26.44 \\
(13.04)\end{array}$ & $\begin{array}{c}21.29 \\
(10.38)\end{array}$ & $\begin{array}{c}22.24 \\
(10.25)\end{array}$ & $\begin{array}{c}12.63 \\
(13.73)\end{array}$ & $\begin{array}{c}18.93 \\
(10.94)\end{array}$ & $\begin{array}{c}3.89 \\
(10.29)\end{array}$ & $\begin{array}{c}14.45 \\
(10.18)\end{array}$ \\
\hline $\mathrm{p}$-value $(D=1-D)$ & & 0.61 & 0.31 & 0.67 & 0.85 & 0.23 & 0.11 & 0.00 & 0.49 \\
\hline$N$ & 1,942 & 1,942 & 1,942 & 1,942 & 1,942 & 1,942 & 1,942 & 1,942 & 1,942 \\
\hline p-value $(\mathrm{OLS}=\mathrm{IV})$ & 0.21 & 0.39 & 0.33 & 0.42 & 0.20 & 0.06 & 0.21 & 0.05 & 0.71 \\
\hline Share $D$ & & 0.78 & 0.23 & 0.50 & 0.55 & 0.79 & 0.41 & 0.58 & 0.52 \\
\hline Fstat & 76.45 & 38.20 & 31.49 & 34.32 & 29.04 & 31.21 & 32.82 & 32.31 & 36.95 \\
\hline Covariates \& FEs & $\checkmark$ & $\checkmark$ & $\checkmark$ & $\checkmark$ & $\checkmark$ & $\checkmark$ & $\checkmark$ & $\checkmark$ & $\checkmark$ \\
\hline Area FEs & & & & & & & & $\checkmark$ & $\checkmark$ \\
\hline
\end{tabular}

Notes: Table presents OLS and IV regression coefficients (see Table 1 and 2 notes). Column (1) replicates base model for doctor visits. (2)-(10) assesses heterogeneity by multiplying the variable of interest (LEP) with an indicator $D$ that is 1 if column header is true (share of $D$ in the total sample is given in the bottom section): (2) household income is below median Australian household income, (3) Means-tested health care card, (4) high SES neighbourhood SEIFA score (score higher than 1.014.4), (5) Overprotection score larger than 3; (6) warmth parenting score larger than 4; (7) if there are no older siblings. (9) uses census data at the postcode level to calculate whether there is at least one medical practitioner or (10) teacher who speaks the COB language at home.

Source: LSAC (2004-2016), ASJP v18, Australian Census 2011, own calculations.

We test several hypotheses that may explain the higher GP utilisation by children of LEP parents and present our results in Table 3. To decompose the main effect, we augment our main specification with both interactions LEP $\times(1-D)$ and LEP $\times D$ (and the IV accordingly), where $D$ is an indicator of whether the column header is true, such that the weighted average is equal to the main effect (column $1)$.

First, we examine the possibility of heterogeneity by income or socioeconomic status. Although we control for household income and other measures of socioeconomic status in column 4 of Table 2, it is still possible for income to moderate the LEP effect. In column (1) we show the base estimates of the effect of LEP on child's GP visits. In column (2) we show that there is no significant difference between children from families with below and above median household income (OLS $p=0.97$;V $p=0.61$ ). Similarly, when we examine an alternative measure of low income - whether the parent holds a government concession means-tested health care card (HCC) (column 3) there again is no significant difference. ${ }^{16}$ Because it has been shown that local area matters for the intergenerational transmission of human capital (Chetty et al., 2014), we test whether differences in the LEP effect on GP usage exists by neighbourhood socioeconomic status (measured by SEIFA). We again find that there are no significant differences (column 4). We return to geographic effects below.

\footnotetext{
${ }^{16}$ GPs are given financial incentives to charge health care card (HCC) holders nothing for a consultation (known as bulk-billing), which may make HHC holders more likely to see a GP. However, there are similar incentives to bulk-bill patients under 16, so the insignificant difference by HCC status is not surprising in this sample of children.
} 
Next we explore whether the effect of parental LEP on GP visits differs by parenting style which has recently received renewed interest by economists (e.g. Doepke and Zilibotti, 2017; Cobb-Clark, Salamanca and Zhu, 2016). It is possible, for example, that LEP is correlated with a certain type of parenting style (such as overprotectiveness), which make parents more likely to take their child to the doctor for even minor health issues. Nevertheless, we cannot detect (significant) differences in the LEP effect by the parent's overprotectiveness (column 6), nor do we see any difference by whether they have a warm parenting style (column 7); again explanations of these variables can be found in Table C2.

Third, we explore a parent's uncertainty. For example, LEP may be correlated with lower levels of health literacy, which could lead to greater uncertainty when faced with the child's health condition. This uncertainty, or lack of knowledge, may result in an increased reliance on doctors for a wider range of health issues, including conditions for which there is typically no treatment (e.g. colds). We hypothesise that parents would exhibit greater uncertainty if this were their first child, so we estimate the LEP effect by whether the child has any older siblings. Consistent with this hypothesis, we find that the effect is considerably larger (about 2 times larger for the IV model) when the child has no older sibling, but the difference is only weakly significant $(p=0.1)$. The OLS model suggests no significant difference by the presence of an older sibling (although there may be alternative explanations for this, e.g. see a discussion on birth order and child investments in Black, Devereux and Salvanes, 2005; Conley and Glauber, 2006).

Although communication problems may present a barrier to accessing medical services, it may be possible for immigrants to access a doctor who speaks their native language, thereby reducing communication barriers. Therefore, we augment our data with 2011 Census information to test if the main effect differs by whether there is at least one doctor in the child's local area from the same country of origin as the parent. ${ }^{17}$ To control for regional differences in health care utilisation, we control for local area fixed effects in all subsequent models. As shown in column (9), the LEP effect is considerably greater when there is a doctor from the parent's COB in the neighbourhood, compared to when there is no doctor from the parent's COB. For the IV model, the effect is about 8 times larger when there is a same COB doctor and this difference is highly significant $(p=0.0)$. For the OLS model, the results are in the same direction but only weakly significant $(p=0.1)$. These results imply that parents with LEP may be going more to the GP when he or she speaks their own language. Because we only know the availability of own-language doctors in the local area (and not whether they are seeing these doctors), our results are merely suggestive. To strengthen the credibility of these results we perform a placebo test: we examine whether having a teacher (at a primary or secondary school) working in the local area who is from the same COB as the parent influences the LEP effect. In general, we would not expect a teacher who speaks the same language as parents with LEP to directly influence their children's GP visits, and the insignificant differences shown in column (10) confirm this.

\footnotetext{
${ }^{17}$ The number of doctors in the local area comes from the 2011 Census. We use the number of individuals working as "medical practitioners" by their COB and the local area in which they work, as measured by Statistical Area 3 - SA3. There are 358 spatial SA3 regions in Australia, each with about 30,000 to 130,000 persons.
} 


\subsection{GPs as a source of parenting information?}

Table 4: LEP ON PARENTING INFORMATION SOURCES BY AVAILABILITY OF OWN-LANGUAGE DOCTOR IN LOCAL AREA

\begin{tabular}{|c|c|c|c|c|c|c|c|c|}
\hline \multirow{4}{*}{$\begin{array}{l}\text { Dependent variables } \\
\text { heterogeneity: } D= \\
\end{array}$} & $\begin{array}{l}\text { Probabi } \\
\text { if own }\end{array}$ & $\begin{array}{l}y \times 100 \\
\text { nguage }\end{array}$ & $\begin{array}{l}f \text { gettins } \\
\text { ctor in }\end{array}$ & $\begin{array}{l}\text { parentin } \\
\text { stcode a }\end{array}$ & $\begin{array}{l}\text { informa } \\
\text { rea }\end{array}$ & from v & pus s & \\
\hline & \multicolumn{8}{|c|}{ Getting parenting informations from } \\
\hline & \multicolumn{2}{|c|}{ GP } & \multicolumn{2}{|c|}{ Friends } & \multicolumn{2}{|c|}{ Non-resident family } & \multicolumn{2}{|c|}{ Other professionals } \\
\hline & (1) & $(2)$ & $(3)$ & (4) & (5) & (6) & (7) & (8) \\
\hline \multicolumn{9}{|l|}{ OLS } \\
\hline $\mathrm{LEP} \times D$ & $\begin{array}{c}9.34 \\
(4.79)\end{array}$ & $\begin{array}{l}13.98 \\
(6.06)\end{array}$ & $\begin{array}{c}1.99 \\
(4.96)\end{array}$ & $\begin{array}{c}6.02 \\
(6.10)\end{array}$ & $\begin{array}{l}-3.63 \\
(5.09)\end{array}$ & $\begin{array}{l}-8.41 \\
(6.28)\end{array}$ & $\begin{array}{l}-4.75 \\
(3.16)\end{array}$ & $\begin{array}{l}-2.57 \\
(3.93)\end{array}$ \\
\hline $\mathrm{LEP} \times(1-D)$ & & $\begin{array}{c}2.43 \\
(6.45)\end{array}$ & & $\begin{array}{l}-4.01 \\
(6.98)\end{array}$ & & $\begin{array}{c}3.52 \\
(7.08)\end{array}$ & & $\begin{array}{l}-7.99 \\
(4.27)\end{array}$ \\
\hline $\begin{array}{l}\mathrm{p} \text {-value } \\
(D=1-D)\end{array}$ & & 0.15 & & 0.24 & & 0.17 & & 0.30 \\
\hline \multicolumn{9}{|l|}{ IV } \\
\hline $\operatorname{LEP} \times D$ & $\begin{array}{c}15.61 \\
(17.67)\end{array}$ & $\begin{array}{c}27.65 \\
(20.83)\end{array}$ & $\begin{array}{l}-22.30 \\
(18.68)\end{array}$ & $\begin{array}{l}-19.24 \\
(21.61)\end{array}$ & $\begin{array}{c}-6.93 \\
(18.43)\end{array}$ & $\begin{array}{l}-10.58 \\
(21.18)\end{array}$ & $\begin{array}{l}-26.80 \\
(12.84)\end{array}$ & $\begin{array}{c}-26.12 \\
(14.94)\end{array}$ \\
\hline $\mathrm{LEP} \times(1-D)$ & & $\begin{array}{c}2.18 \\
(17.23)\end{array}$ & & $\begin{array}{c}-25.72 \\
(18.84)\end{array}$ & & $\begin{array}{c}-2.85 \\
(18.57)\end{array}$ & & $\begin{array}{l}-27.55 \\
(12.52)\end{array}$ \\
\hline $\begin{array}{l}\mathrm{p} \text {-value } \\
(D=1-D)\end{array}$ & & 0.09 & & 0.69 & & 0.62 & & 0.89 \\
\hline$N$ & 1,942 & 1,942 & 1,942 & 1,942 & 1,942 & 1,942 & 1,942 & 1,942 \\
\hline $\mathrm{p}$-value $(\mathrm{OLS}=\mathrm{IV})$ & 0.71 & 0.55 & 0.18 & 0.42 & 0.85 & 0.90 & 0.08 & 0.22 \\
\hline F-stat & 72.75 & 32.30 & 72.75 & 32.30 & 72.75 & 32.30 & 72.75 & 32.30 \\
\hline Covariates \& FEs & $\checkmark$ & $\checkmark$ & $\checkmark$ & $\checkmark$ & $\checkmark$ & $\checkmark$ & $\checkmark$ & $\checkmark$ \\
\hline Area FEs & $\checkmark$ & $\checkmark$ & $\checkmark$ & $\checkmark$ & $\checkmark$ & $\checkmark$ & $\checkmark$ & $\checkmark$ \\
\hline
\end{tabular}

Notes: Table presents comparable regressions to Table 3 notes, using sources of parenting information as an outcome and testing heterogeneity by availability of a own-language doctor in the local area.

Source: LSAC (2004-2016), ASJP v18, Australian Census 2011, own calculations.

Given the positive influence of having a GP in one's local area on the parental LEP effect on GP visits, we wonder whether parents with LEP are visiting GPs for more than just their child's health care needs. Specifically, we want to know if parents with LEP may be visiting GPs (especially those who speak their own language) to get parenting information. Although most local councils in Australia provide parent support groups, these are almost always held in English. Immigrants with LEP may have a small social network of people they can communicate with and rely on for information on raising young children. The LSAC survey asks parents: "(apart from your partner) what are your 3 most important sources of information about parenting or caring for child?" In Table 4 we show the effect of parental LEP on the probability that parents get their parenting information from the following sources: GPs, friends, non-resident family, and other professionals. As in the previous table, we also estimate whether the probability differs by having at least one medical practitioner in the family's local area from the same COB as the parent (i.e., own-language doctor).

Column (1) of Table 4 indicates that parents with LEP are more likely to get their parenting information from a GP than parents who are proficient in English. The OLS results suggest a 9.3 percentage point 
increase $(p<0.05)$ and the IV estimates suggest a 15.6 percentage point increase (although insignificant). Column (2) shows that this effect is driven almost exclusively by those who have at least one own-language doctor in the local area. The OLS and IV estimates indicate that when there is an own-language doctor in the local area, LEP parents are about 6 and 13 times respectively, more likely to get parenting information from their GP than when there is no own-language doctor (OLS $p=0.15$; IV $p=0.09$ ). These results support the hypothesis that parents with LEP take their children to the GP more than other parents for general parenting information, particularly if they are able to speak to the doctor in their native language. In contrast, our 'placebo' results in columns 3 to 8 show that parents with LEP are not any more likely to get parenting information from their friends, family or other professionals; indeed, the sign is almost always negative and sometimes statistically significant. As expected, having an own-language doctor in the local area does not influence these relationships.

\subsection{Discussion and conclusions}

This is the first study that uses detailed administrative health records and survey measures to examine the intergenerational effects of limited language skills on children's health outcomes. To address endogeneity concerns surrounding language proficiency, we use a variety of estimation methods, including an instrumental variable approach that exploits the discontinuity in language deficiency that arises when immigrants arrive after the childhood 'critical period' of language acquisition. Our results demonstrate that parental limited English proficiency (LEP) has a large and positive impact on the health care utilisation of children. The OLS estimates indicate that children of parents with LEP incure child Medicare costs from parental LEP are about $25 \%$ (or $\$ 600$ ) higher, while the IV estimates indicate that costs are about $90 \%$ (or $\$ 2,280$ ) higher over a 10-year period. Statistically, the main IV estimates are only weakly different from the OLS estimates; in accordance with the literature, we interpret our IV and OLS estimates as upper- and lower-bound estimates respectively. If we extrapolate these additional Medicare costs to the population of dependent children (0 age to 14 years) whose mother has LEP (67,407 children), backof-the-envelope calculations suggest that the average cost to the Australian Medicare system amounts to approximately $\$ 4$ to 15 million per year (based on OLS and IV estimates respectively). ${ }^{18}$ This is a nontrivial expense, and demonstrates that there are considerable and previously ignored intergenerational costs of LEP. One alternative use of these public funds is to invest them in English language training. For $\$ 15$ million, the government could fund, at market price, a 13-week full-time English language course to about 7,000 people each year. ${ }^{19}$

One positive take-away from our results is that children are not any sicker if they have a parent with LEP. They are not more likely to visit the hospital, nor do they have additional physical or mental health

\footnotetext{
${ }^{18}$ The number of dependent children to a mother with LEP was sourced from the Australian Bureau of Statistics (ABS) 2011 Census.

${ }^{19}$ This calculation is based on 13 weeks of tuition from a popular language course offered by Federation Technology Institute in Melbourne for $\$ 2,223$, see https://www.languagecourse.net/school-fti---federation-technology-institutemelbourne.php3 (asof 1May2019). While this example is arbitrary and the government could provide training for considerably less than private tuition costs, this exercise provides a useful benchmark.
} 
problems or disabilities. Therefore, although there are considerable intergenerational medical costs (borne by the public), there does not appear to be any intergenerational health capital cost arising from parental LEP (at least under a free and universal health care system). Our research is unique in that it examines the health outcomes of immigrants' children who are covered by universal public health insurance. This eliminates the possibility that insurance coverage may be a key reason why LEP influences health care utilisation and health outcomes. Studies in the U.S. have shown that health insurance uptake for both parents and children is reduced by LEP (Dillender, 2017), and that parental LEP is associated with children having reduced access to needed medical care (Weinick and Krauss, 2000). We show that when all children are covered under public health insurance there are, at least in our setting, no barriers to accessing needed health care and no adverse health outcomes as a result of parental LEP. Further, we show that there is no difference in the effect of parental LEP by income or socioeconomic status. Our finding that the language skills of immigrant parents has no effect on children's health, builds on the work that demonstrates parental education has little causal impact on children's health (e.g., Lindeboom, Llena-Nozal and van Der Klaauw, 2009).

The higher Medicare costs arising from parental LEP appear to be driven exclusively by more visits to a GP. We show that this occurs with much greater frequency if there is a doctor in the local area who is from the same COB as the parent. In other words, our results suggest that the LEP effect on GP utilisation is much greater in areas where communication barriers are likely to be lower. One possible explanation for the higher GP visits might be a greater reliance on GPs as trusted sources for parenting information. Indeed we find that parents with LEP are significantly more likely to get their parenting information from a GP if there is an own-language doctor in the local area (by about $48 \%$ at the mean). Although many free parenting groups and maternal health clinics operate around Australia, they pose considerable language barriers for parents with LEP. Therefore, it is possible that a lack of parentingor social-networks can explain the higher use of GPs for parenting information. Related studies have demonstrated this importance of 'networks' for sharing information, for example about the availability of public maternity services (Aizer and Currie, 2004). Our study provides another perspective: that a lack of information networks for immigrant parents can have spillover consequences for public health expenditures.

While our findings are positive from an equity and public health perspective, our results also indicate that parental LEP may result in an inefficient allocation of public health resources. Improved English language skills would likely bring economic benefits to both the individual immigrant and the public purse. Potential policy responses might be to foster English language classes and programs that support immigrants with own-language social or parenting networks to reduce the reliance on GPs for parenting information. 


\section{References}

ABS. 2016. "Cultural Diversity in Australia, 2016." Australian Bureau of Statisitcs . https:

//www.abs.gov. au/ausstats/abs@.nsf/Lookup/by\%20Subject/2071.0 2016 Main\%20Features $\sim$ Cultural\%20Diversity\%20Article 60

Aizer, Anna and Janet Currie. 2004. "Networks or neighborhoods? Correlations in the use of publicly-funded maternity care in California." Journal of Public Economics 88(12):2573-2585.

Altonji, Joseph G., Todd E. Elder and Christopher R. Taber. 2005a." "An evaluation of instrumental variable strategies for estimating the effects of catholic schooling." Journal of Human Resources 40(4):791-821.

Altonji, Joseph G., Todd E. Elder and Christopher R. Taber. 2005b. "Selection on observed and unobserved variables: Assessing the effectiveness of Catholic schools." Journal of Political Economy 113(1):151-184.

Altonji, Joseph G., Todd E. Elder and Christopher R. Taber. 2008. "Using selection on observed variables to assess bias from unobservables when evaluating swan-ganz catheterization." American Economic Review 98(2):345-50.

Aoki, Yu and Lualhati Santiago. 2018. "Speak better, do better? Education and health of migrants in the UK." Labour Economics 52:1-17.

Basu, Anirban and Willard G. Manning. 2009. "Issues for the next generation of health care cost analyses." Medical Care 47(7 Supplement 1):S109-S114.

Black, Sandra E., Paul J. Devereux and Kjell G. Salvanes. 2005. "The more the merrier? The effect of family size and birth order on children's education." Quarterly Journal of Economics 120(2):669-700.

Bleakley, Hoyt and Aimee Chin. 2004. "Language skills and earnings: Evidence from childhood immigrants." Review of Economics and Statistics 86(2):481-496.

Bleakley, Hoyt and Aimee Chin. 2008. "What holds back the second generation? The intergenerational transmission of language human capital among immigrants." Journal of Human Resources 43(2):267-298.

Buntin, Melinda B. and Alan M. Zaslavsky. 2004. "Too much ado about two-part models and transformation?: Comparing methods of modeling Medicare expenditures." Journal of Health Economics 23(3):525-542.

Cantoni, Eva and Elvezio Ronchetti. 2001. "Robust inference for generalized linear models." Journal of the American Statistical Association 96(455):1022-1030.

Case, Anne, Angela Fertig and Christina Paxson. 2005. "The lasting impact of childhood health and circumstance." Journal of Health Economics 24(2):365-389.

Case, Anne, Darren Lubotsky and Christina Paxson. 2002. "Economic status and health in childhood: The origins of the gradient." American Economic Review 92(5):1308-1334.

Casey, Teresa and Christian Dustmann. 2008. "Intergenerational transmission of language capital and economic outcomes." Journal of Human Resources 43(3):660-687.

Chetty, Raj, Nathaniel Hendren, Patrick Kline and Emmanuel Saez. 2014. "Where is the land of opportunity? The geography of intergenerational mobility in the United States." Quarterly Journal of Economics 129(4):1553-1623.

Clarke, Andrew and Ingo E. Isphording. 2017. "Language Barriers and Immigrant Health." Health Economics 26(6):765-778.

Cobb-Clark, Deborah A., Nicolas Salamanca and Anna Zhu. 2016. "Parenting style as an investment in human development." Journal of Population Economics pp. 1-38.

Cole, Tim J., Katherine M. Flegal, Dasha Nicholls and Alan A. Jackson. 2007. "Body mass index cut offs to define thinness in children and adolescents: international survey." British Medical Journal $335(7612): 1-8$.

Conley, Dalton and Rebecca Glauber. 2006. "Parental educational investment and children's academic risk estimates of the impact of sibship size and birth order from exogenous variation in fertility." Journal of Human Resources 41(4):722-737.

Currie, Janet and Mark Stabile. 2003. "Socioeconomic status and child health: why is the relationship stronger for older children?" American Economic Review 93(5):1813-1823.

Currie, Janet, Mark Stabile, Phongsack Manivong and Leslie L. Roos. 2010. "Child health and young adult outcomes." Journal of Human Resources 45(3):517-548. 
Cutler, David M. and Adriana Lleras-Muney. 2006. "Education and health: evaluating theories and evidence." NBER .

Cutler, David M. and Adriana Lleras-Muney. 2010. "Understanding differences in health behaviors by education." Journal of Health Economics 29(1):1-28.

Dillender, Marcus. 2017. "English Skills and the Health Insurance Coverage of Immigrants." American Journal of Health Economics 3(3):312-345.

Doepke, Matthias and Fabrizio Zilibotti. 2017. "Parenting with style: Altruism and paternalism in intergenerational preference transmission." Econometrica 85(5):1331-1371.

Eichler, Klaus, Simon Wieser and Urs Brügger. 2009. "The costs of limited health literacy: a systematic review." International Journal of Public Health 54(5):313.

Groger, Jeff and Stephen J. Trejo. 2002. Falling behind or moving up? The intergenerational progress of Mexican Americans. San Francisco, CA: Public Policy Institute of California.

Grossman, Michael. 1972. "On the concept of health capital and the demand for health." Journal of Political Economy 80(2):223-255.

Guven, Cahit and Asadul Islam. 2015. "Age at migration, language proficiency, and socioeconomic outcomes: evidence from Australia." Demography 52(2):513-542.

Hack, Maureen, Nancy K. Klein and H. Gerry Taylor. 1995. "Long-term developmental outcomes of low birth weight infants." The future of children 5(1):176-196.

Hampers, Louis C., Susie Cha, David J. Gutglass, Steven E. Krug, Helen J. Binns et al. 1999. "The effect of price information on test-ordering behavior and patient outcomes in a pediatric emergency department." Pediatrics 103(4):877-882.

Heckman, James J. 1976. The common structure of statistical models of truncation, sample selection and limited dependent variables and a simple estimator for such models. In Annals of Economic and Social Measurement, Volume 5, number 4. NBER pp. 475-492.

Holman, Eric W., Cecil H. Brown, Søren Wichmann, André Müller, Viveka Velupillai, Harald Hammarström, Sebastian Sauppe, Hagen Jung, Dik Bakker, Pamela Brown et al. 2011. "Automated dating of the world's language families based on lexical similarity." Current Anthropology 52(6):000-000.

Holman, Eric W., Søren Wichmann, Cecil H. Brown, Viveka Velupillai, André Müller and Dik Bakker. 2008. "Explorations in automated language classification." Folia Linguistica 42(3-4):331-354.

Isphording, Ingo E. and Sebastian Otten. 2014. "Linguistic barriers in the destination language acquisition of immigrants." Journal of Economic Behavior EG Organization 105:30-50.

Jacobs, Elizabeth, Alice Hm Chen, Leah S. Karliner, Niels Agger-Gupta and Sunita Mutha. 2006. "The need for more research on language barriers in health care: a proposed research agenda." Milbank Quarterly 84(1):111-133.

John-Baptiste, Ava, Gary Naglie, George Tomlinson, Shabbir M.H. Alibhai, Edward Etchells, Angela Cheung, Moira Kapral, Wayne L. Gold, Howard Abrams, Maria Bacchus et al. 2004. "The effect of English language proficiency on length of stay and in-hospital mortality." Journal of General Internal Medicine 19(3):221-228.

Jones, Andrew M. 2000. Health econometrics. In Handbook of health economics. Vol. 1 Elsevier pp. 265-344.

Kosmidis, Ioannis and David Firth. 2009. "Bias reduction in exponential family nonlinear models." Biometrika 96(4):793-804.

Krieger, Tim, Laura Renner and Jens Ruhose. 2018. "Long-term relatedness between countries and international migrant selection." Journal of International Economics 113:35-54.

Kunz, Johannes S. 2016. "Analyzing Educational Achievement Differences between Second-Generation Immigrants: Comparing Germany and German-Speaking Switzerland." German Economic Review $17(1): 61-91$.

Kunz, Johannes S., Kevin E. Staub and Rainer Winkelmann. 2017. "Estimating Fixed Effects: Perfect Prediction and Bias in Binary Response Panel Models, with an Application to the Hospital Readmissions Reduction Program." IZA DP No. 11182 .

Kunz, Johannes S. and Rainer Winkelmann. 2017. "An econometric model of healthcare demand with nonlinear pricing." Health Economics 26(6):691-702.

Lee, Lung-Fei. 1978. "Unionism and wage rates: A simultaneous equations model with qualitative and limited dependent variables." International Economic Review 19(2):415-433. 
Lemmermann, Dominique and Regina T. Riphahn. 2018. "The causal effect of age at migration on youth educational attainment." Economics of Education Review 63:78-99.

Lenneberg, Eric H. 1967. "The biological foundations of language." Hospital Practice 2(12):59-67.

Lindeboom, Maarten, Ana Llena-Nozal and Bas van Der Klaauw. 2009. "Parental education and child health: Evidence from a schooling reform." Journal of Health Economics 28(1):109-131.

Manning, Willard G. 1998. "The logged dependent variable, heteroscedasticity, and the retransformation problem." Journal of Health Economics 17(3):283-295.

Medicare. 2017. "Department of Health:." Annual Medicare Statistics . http://www.health.gov.au/internet/main/publishing.nsf/Content/Annual-Medicare-Statistics

Nelson, Alan. 2002. "Unequal treatment: confronting racial and ethnic disparities in health care." Journal of the National Medical Association 94(8):666.

Oster, Emily. 2017. "Unobservable selection and coefficient stability: Theory and evidence." Journal of Business \& Economic Statistics pp. 1-18.

Pei, Zhuan, Jörn-Steffen Pischke and Hannes Schwandt. 2018. "Poorly measured confounders are more useful on the left than on the right." Journal of Business 86 Economic Statistics pp. 1-12.

Pohlmeier, Winfried and Volker Ulrich. 1995. "An econometric model of the two-part decisionmaking process in the demand for health care." Journal of Human Resources pp. 339-361.

Soloff, Carol, David Lawrence and Robert Johnstone. 2005. "The Longitudinal Study of Australian Children: an Australian Government initiative. Sample design." Australian Institute of Family Studies Melbourne.

Spolaore, Enrico and Romain Wacziarg. 2009. "The diffusion of development." Quarterly Journal of Economics 124(2):469-529.

Spolaore, Enrico and Romain Wacziarg. September 2017. "Ancestry and Development: New Evidence." Dataset .

Staub, Kevin E. and Rainer Winkelmann. 2013. "Consistent estimation of zero-inflated count models." Health Economics 22(6):673-686.

UN. 2017. 2017 International Migration Report. United Nations: New York.

Van den Berg, Gerard J., Petter Lundborg, Paul Nystedt and Dan-Olof Rooth. 2014. "Critical periods during childhood and adolescence." Journal of the European Economic Association 12(6):1521-1557.

Van Ours, Jan C. and Justus Veenman. 2006. "Age at immigration and educational attainment of young immigrants." Economics Letters 90(3):310-316.

Weinick, Robin M. and Nancy A. Krauss. 2000. "Racial/ethnic differences in children's access to care." American Journal of Public Health 90(11):1771.

Wichmann, Søren, Eric W. Holman, Dik Bakker and Cecil H. Brown. 2010. "Evaluating linguistic distance measures." Physica A: Statistical Mechanics and its Applications 389(17):3632-3639.

Young, Alwyn. 2017. "Consistency without inference: Instrumental variables in practical application." Unpublished manuscript, London: London School of Economics and Political Science. Retrieved from: http://personal. lse. ac. uk/YoungA. 


\section{A Additional results}

In this appendix we present more descriptive information about our sample and omitted results due to space limitations.

Table A1 presents descriptive statistics of our main variables, along with mean comparison by LEP-("treatment" status) and corresponding balance tests for these covariates.

Table A2 presents descriptive statistics of the extended set of parent's characteristics (column 1), along with mean comparison by LEP status (columns 2 and 3). Unconditional coefficient estimates of the characteristic on LEP (balance test) and on log costs (our main outcome variable) are shown in columns 4 and 5 . These estimates correspond with the black and grey plots in Figure 2 (left graph).

In Table A3 we present the detailed first stage estimates. Column (1) shows the first stage in our main IV regressions, column (2) shows the implied first stage in the Oster's approach cf. Table 1 without the instrument, while column (3) disentangles the IV into the linguistic distance and age at arrival components and includes COB regions instead of COB fixed effects in order to demonstrate the independent broad effect of COB. The strength of the first stage is evident in the column (1).

Analogous to these, we present probit regressions in columns (4)-(6). Note, that we estimate bias-reduced probit estimations, an approach developed by Kunz, Staub and Winkelmann (2017), (for the general treatment see Kosmidis and Firth, 2009). These correspond to regression coefficients rather than marginal effects but the sign and significance correspond mostly to those of the linear probability model approximations. Column (4) is used in the robustness test of using the inverse mills ratio selection correction (see Table B3 Column 5, below). Column (5) is used for the Altonji-Elder-Taber bounds in Table 1 Columns 7 and 8. Again, column (6) presents the components of the IV separately and includes the $\mathrm{COB}$ regions for comparison.

Table A4 presents the corresponding coefficient estimates of Figure 2.

Figure A1, shows the evolution of the raw cost gap between children of parents parents who have limited English proficiency (LEP) and those who have English proficiency (EP). The graph on the left plots the unconditional mean health care costs at each age of the child, while the graph on the right plots the (conditional) OLS and IV estimates. In both graphs, the gap in health care utilisation by LEP phases out after the children reach the age of 9 . This may be a time when uncertainty in when to visit a doctor resolves or when parents require less parenting support from doctors. 
Table A1: Descriptive statistics and Differences in means test

BETWEEN PARENTS WITH LIMITED ENGLiSH PROFICIENCY (LEP) AND ENGLISH PROFICIENCY (EP)

\begin{tabular}{|c|c|c|c|c|}
\hline & \multicolumn{3}{|c|}{ Mean } & \multirow[b]{2}{*}{ Difference } \\
\hline & Overall & LEP & EP & \\
\hline & (1) & $(2)$ & (3) & $(4)$ \\
\hline \multicolumn{5}{|l|}{ Children's outcomes, total 10-year } \\
\hline Total 10-year medicare costs in $\$$ & $\begin{array}{c}2623.78 \\
(55.44)\end{array}$ & $\begin{array}{c}3381.86 \\
(203.91)\end{array}$ & $\begin{array}{c}2537.23 \\
(56.87)\end{array}$ & $\begin{array}{c}844.63 \\
(211.30)\end{array}$ \\
\hline Doctor costs in $\$$ & $\begin{array}{c}2395.48 \\
(46.59)\end{array}$ & $\begin{array}{l}2912.01 \\
(156.76)\end{array}$ & $\begin{array}{c}2336.50 \\
(48.54)\end{array}$ & $\begin{array}{c}575.51 \\
(163.81)\end{array}$ \\
\hline Pharmaceutical costs in $\$$ & $\begin{array}{l}228.30 \\
(18.40)\end{array}$ & $\begin{array}{l}469.85 \\
(75.48)\end{array}$ & $\begin{array}{l}200.72 \\
(18.50)\end{array}$ & $\begin{array}{l}269.12 \\
(77.56)\end{array}$ \\
\hline \multicolumn{5}{|l|}{ Children's characteristics } \\
\hline Male (Yes/No) & $\begin{array}{c}0.52 \\
(0.01)\end{array}$ & $\begin{array}{c}0.47 \\
(0.04)\end{array}$ & $\begin{array}{c}0.52 \\
(0.01)\end{array}$ & $\begin{array}{c}-0.06 \\
(0.04)\end{array}$ \\
\hline Age in month & $\begin{array}{l}32.17 \\
(0.55)\end{array}$ & $\begin{array}{l}31.19 \\
(1.72)\end{array}$ & $\begin{array}{c}32.28 \\
(0.58)\end{array}$ & $\begin{array}{l}-1.10 \\
(1.81)\end{array}$ \\
\hline First cohort (Yes/No) & $\begin{array}{c}0.49 \\
(0.01)\end{array}$ & $\begin{array}{c}0.47 \\
(0.04)\end{array}$ & $\begin{array}{c}0.49 \\
(0.01)\end{array}$ & $\begin{array}{l}-0.02 \\
(0.04)\end{array}$ \\
\hline \multicolumn{5}{|l|}{ Parent's characteristics } \\
\hline Male (Yes/No) & $\begin{array}{c}0.03 \\
(0.00)\end{array}$ & $\begin{array}{c}0.02 \\
(0.01)\end{array}$ & $\begin{array}{c}0.03 \\
(0.00)\end{array}$ & $\begin{array}{l}-0.01 \\
(0.01)\end{array}$ \\
\hline Age (in years) & $\begin{array}{l}34.21 \\
(0.13)\end{array}$ & $\begin{array}{l}33.40 \\
(0.43)\end{array}$ & $\begin{array}{l}34.30 \\
(0.13)\end{array}$ & $\begin{array}{l}-0.90 \\
(0.45)\end{array}$ \\
\hline Born english-speaking country (Yes/No) & $\begin{array}{c}0.56 \\
(0.01)\end{array}$ & $\begin{array}{c}0.08 \\
(0.02)\end{array}$ & $\begin{array}{c}0.62 \\
(0.01)\end{array}$ & $\begin{array}{l}-0.54 \\
(0.02)\end{array}$ \\
\hline ASJP Language distance $(0-1)$ & $\begin{array}{c}0.41 \\
(0.01)\end{array}$ & $\begin{array}{c}0.91 \\
(0.02)\end{array}$ & $\begin{array}{c}0.35 \\
(0.01)\end{array}$ & $\begin{array}{c}0.56 \\
(0.02)\end{array}$ \\
\hline Age at arrival (in years) & $\begin{array}{l}18.80 \\
(0.24)\end{array}$ & $\begin{array}{l}25.48 \\
(0.43)\end{array}$ & $\begin{array}{l}18.03 \\
(0.26)\end{array}$ & $\begin{array}{c}7.44 \\
(0.50)\end{array}$ \\
\hline \multicolumn{5}{|l|}{ Decade of arrival } \\
\hline $70 \mathrm{~s}$ & $\begin{array}{c}0.17 \\
(0.01)\end{array}$ & $\begin{array}{c}0.01 \\
(0.01)\end{array}$ & $\begin{array}{c}0.19 \\
(0.01)\end{array}$ & $\begin{array}{c}-0.18 \\
(0.01)\end{array}$ \\
\hline $80 \mathrm{~s}$ & $\begin{array}{c}0.23 \\
(0.01)\end{array}$ & $\begin{array}{c}0.11 \\
(0.02)\end{array}$ & $\begin{array}{c}0.24 \\
(0.01)\end{array}$ & $\begin{array}{c}-0.14 \\
(0.02)\end{array}$ \\
\hline $90 \mathrm{~s}$ & $\begin{array}{c}0.42 \\
(0.01)\end{array}$ & $\begin{array}{c}0.63 \\
(0.03)\end{array}$ & $\begin{array}{c}0.40 \\
(0.01)\end{array}$ & $\begin{array}{c}0.23 \\
(0.04)\end{array}$ \\
\hline $00 \mathrm{~s}$ & $\begin{array}{c}0.11 \\
(0.01)\end{array}$ & $\begin{array}{c}0.25 \\
(0.03)\end{array}$ & $\begin{array}{c}0.09 \\
(0.01)\end{array}$ & $\begin{array}{c}0.16 \\
(0.03)\end{array}$ \\
\hline$N(\%)$ & 1,942 & $199(10 \%)$ & $1,743(90 \%)$ & 1,942 \\
\hline
\end{tabular}

Notes: Table presents descriptives: means and standard deviations for the overall (Column 1), the limited English proficiency (LEP) (2) and English proficiency (EP) (3) sample. Column (4) presents the "balance" regression estimate of characteristic on the LEP indicator, all with robust standard errors.

Source: LSAC (2004-2016), ASJP linguistic data (v18), own calculations. 


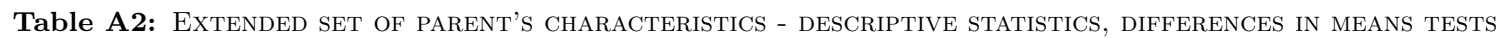
BETWEEN PARENTS WITH LIMITED ENGLiSH PROFICIENCY (LEP) AND ENGLiSH PROFICIENCY (EP)

\begin{tabular}{|c|c|c|c|c|c|}
\hline & \multicolumn{3}{|c|}{ Mean } & \multicolumn{2}{|c|}{ OLS } \\
\hline & Mean & LEP & $\mathrm{EP}$ & Difference & Log costs \\
\hline & $(1)$ & $(2)$ & $(3)$ & $(4)$ & $(5)$ \\
\hline $\begin{array}{l}\text { Main parent's characteristics } \\
\text { Less than high school educated (Yes/No) }\end{array}$ & $\begin{array}{c}0.16 \\
(0.01)\end{array}$ & $\begin{array}{c}0.48 \\
(0.04)\end{array}$ & $\begin{array}{c}0.12 \\
(0.01)\end{array}$ & $\begin{array}{c}0.35 \\
(0.04)\end{array}$ & $\begin{array}{l}-0.00 \\
(0.06)\end{array}$ \\
\hline Unemployed (Yes/No) & $\begin{array}{c}0.04 \\
(0.00)\end{array}$ & $\begin{array}{c}0.03 \\
(0.01)\end{array}$ & $\begin{array}{c}0.04 \\
(0.00)\end{array}$ & $\begin{array}{l}-0.01 \\
(0.01)\end{array}$ & $\begin{array}{l}-0.16 \\
(0.11)\end{array}$ \\
\hline Not in labor force (Yes/No) & $\begin{array}{c}0.49 \\
(0.01)\end{array}$ & $\begin{array}{c}0.80 \\
(0.03)\end{array}$ & $\begin{array}{c}0.46 \\
(0.01)\end{array}$ & $\begin{array}{c}0.34 \\
(0.03)\end{array}$ & $\begin{array}{c}0.07 \\
(0.04)\end{array}$ \\
\hline Means-tested health care card (Yes/No) & $\begin{array}{c}0.23 \\
(0.01)\end{array}$ & $\begin{array}{c}0.47 \\
(0.04)\end{array}$ & $\begin{array}{c}0.20 \\
(0.01)\end{array}$ & $\begin{array}{c}0.27 \\
(0.04)\end{array}$ & $\begin{array}{c}0.05 \\
(0.05)\end{array}$ \\
\hline Below median household income & $\begin{array}{c}0.84 \\
(0.01)\end{array}$ & $\begin{array}{c}0.99 \\
(0.01)\end{array}$ & $\begin{array}{c}0.82 \\
(0.01)\end{array}$ & $\begin{array}{c}0.14 \\
(0.01)\end{array}$ & $\begin{array}{c}0.19 \\
(0.06)\end{array}$ \\
\hline Self assessed health (1 - 5 poor $)$ & $\begin{array}{c}2.63 \\
(0.02)\end{array}$ & $\begin{array}{c}2.40 \\
(0.09)\end{array}$ & $\begin{array}{c}2.65 \\
(0.02)\end{array}$ & $\begin{array}{c}-0.18 \\
(0.07)\end{array}$ & $\begin{array}{l}-0.10 \\
(0.02)\end{array}$ \\
\hline Depression scale (0 - 5 depressed $)$ & $\begin{array}{c}1.69 \\
(0.02)\end{array}$ & $\begin{array}{c}1.71 \\
(0.06)\end{array}$ & $\begin{array}{c}1.69 \\
(0.02)\end{array}$ & $\begin{array}{c}0.01 \\
(0.04)\end{array}$ & $\begin{array}{c}0.03 \\
(0.04)\end{array}$ \\
\hline Any medical condition (Yes/No) & $\begin{array}{c}0.21 \\
(0.01)\end{array}$ & $\begin{array}{c}0.15 \\
(0.03)\end{array}$ & $\begin{array}{c}0.22 \\
(0.01)\end{array}$ & $\begin{array}{c}-0.07 \\
(0.03)\end{array}$ & $\begin{array}{c}0.12 \\
(0.05)\end{array}$ \\
\hline Lives in non-urban area (Yes/No) & $\begin{array}{c}0.25 \\
(0.01)\end{array}$ & $\begin{array}{c}0.09 \\
(0.02)\end{array}$ & $\begin{array}{c}0.27 \\
(0.01)\end{array}$ & $\begin{array}{c}-0.18 \\
(0.02)\end{array}$ & $\begin{array}{l}-0.34 \\
(0.05)\end{array}$ \\
\hline Disadvantaged area score (Std) & $\begin{array}{c}-0.18 \\
(0.02)\end{array}$ & $\begin{array}{c}-0.06 \\
(0.08)\end{array}$ & $\begin{array}{l}-0.20 \\
(0.03)\end{array}$ & $\begin{array}{c}0.14 \\
(0.08)\end{array}$ & $\begin{array}{c}-0.02 \\
(0.02)\end{array}$ \\
\hline Overprotection score (1 - 5 highly) & $\begin{array}{c}3.57 \\
(0.02)\end{array}$ & $\begin{array}{c}3.58 \\
(0.10)\end{array}$ & $\begin{array}{c}3.57 \\
(0.02)\end{array}$ & $\begin{array}{c}0.00 \\
(0.05)\end{array}$ & $\begin{array}{c}0.11 \\
(0.03)\end{array}$ \\
\hline Warm parenting score ( 1 - 5 warm $)$ & $\begin{array}{c}4.48 \\
(0.01)\end{array}$ & $\begin{array}{c}4.36 \\
(0.04)\end{array}$ & $\begin{array}{c}4.49 \\
(0.01)\end{array}$ & $\begin{array}{l}-0.12 \\
(0.05)\end{array}$ & $\begin{array}{c}0.14 \\
(0.04)\end{array}$ \\
\hline $\begin{array}{l}\text { Second parent's characteristics } \\
\text { Single parent household (Yes/No) }\end{array}$ & $\begin{array}{c}0.09 \\
(0.01)\end{array}$ & $\begin{array}{c}0.12 \\
(0.02)\end{array}$ & $\begin{array}{c}0.08 \\
(0.01)\end{array}$ & $\begin{array}{c}0.04 \\
(0.02)\end{array}$ & $\begin{array}{l}-0.02 \\
(0.07)\end{array}$ \\
\hline Limited english proficiency (Yes/No) & $\begin{array}{c}0.06 \\
(0.01)\end{array}$ & $\begin{array}{c}0.39 \\
(0.04)\end{array}$ & $\begin{array}{c}0.02 \\
(0.00)\end{array}$ & $\begin{array}{c}0.37 \\
(0.04)\end{array}$ & $\begin{array}{c}0.41 \\
(0.08)\end{array}$ \\
\hline Unemployed or not in labor force (Yes/No) & $\begin{array}{c}0.09 \\
(0.01)\end{array}$ & $\begin{array}{c}0.23 \\
(0.03)\end{array}$ & $\begin{array}{c}0.07 \\
(0.01)\end{array}$ & $\begin{array}{c}0.16 \\
(0.03)\end{array}$ & $\begin{array}{c}0.10 \\
(0.08)\end{array}$ \\
\hline
\end{tabular}

Notes: See Table A1's notes. Additionally, Column (5) presents a regression of log costs (our main outcome) on the variable of interest only. Column (4) and (5) correspond to grey and black lines in Figure 2 left graph. Second parent's characteristics are based on a smaller subset of two-person households $(\mathrm{N}=1,772)$.

Source: LSAC (2004-2016), own calculations. 
Table A3: First-Stage And Propensity score Results

\begin{tabular}{|c|c|c|c|c|c|c|}
\hline & \multicolumn{3}{|c|}{ LPM } & \multicolumn{3}{|c|}{ BRglm probit } \\
\hline & $(1)$ & $(2)$ & $(3)$ & $(4)$ & $(5)$ & $(6)$ \\
\hline $\begin{array}{l}\text { ASJP Language distance: } \\
\text { mother tongue to english }(0-1)\end{array}$ & & & $\begin{array}{l}0.190 \\
(0.017)\end{array}$ & & & $\begin{array}{l}1.596 \\
(0.170)\end{array}$ \\
\hline Age at arrival in years & & & $\begin{array}{c}0.002 \\
(0.002)\end{array}$ & & & $\begin{array}{c}0.036 \\
(0.018)\end{array}$ \\
\hline IV & $\begin{array}{c}0.017 \\
(0.002)\end{array}$ & & & $\begin{array}{c}0.114 \\
(0.018)\end{array}$ & & \\
\hline Father is main carer (Yes/No) & $\begin{array}{l}-0.012 \\
(0.032)\end{array}$ & $\begin{array}{l}-0.025 \\
(0.032)\end{array}$ & $\begin{array}{l}-0.028 \\
(0.033)\end{array}$ & $\begin{array}{l}-0.061 \\
(0.311)\end{array}$ & $\begin{array}{l}-0.121 \\
(0.282)\end{array}$ & $\begin{array}{c}0.007 \\
(0.366)\end{array}$ \\
\hline Age & $\begin{array}{l}-0.005 \\
(0.002)\end{array}$ & $\begin{array}{l}-0.005 \\
(0.002)\end{array}$ & $\begin{array}{l}-0.002 \\
(0.002)\end{array}$ & $\begin{array}{l}-0.067 \\
(0.017)\end{array}$ & $\begin{array}{l}-0.062 \\
(0.018)\end{array}$ & $\begin{array}{l}-0.033 \\
(0.019)\end{array}$ \\
\hline \multicolumn{7}{|l|}{ Decade } \\
\hline $70 \mathrm{~s}$ & $\begin{array}{l}-0.046 \\
(0.016)\end{array}$ & $\begin{array}{l}-0.053 \\
(0.016)\end{array}$ & $\begin{array}{l}-0.024 \\
(0.018)\end{array}$ & $\begin{array}{l}-0.906 \\
(0.143)\end{array}$ & $\begin{array}{l}-1.271 \\
(0.194)\end{array}$ & $\begin{array}{l}-0.195 \\
(0.230)\end{array}$ \\
\hline $80 \mathrm{~s}$ & $\begin{array}{l}-0.100 \\
(0.035)\end{array}$ & $\begin{array}{l}-0.099 \\
(0.036)\end{array}$ & $\begin{array}{l}-0.037 \\
(0.039)\end{array}$ & $\begin{array}{l}-1.660 \\
(0.315)\end{array}$ & $\begin{array}{l}-2.039 \\
(0.366)\end{array}$ & $\begin{array}{c}0.127 \\
(0.349)\end{array}$ \\
\hline $90 \mathrm{~s}$ & $\begin{array}{l}-0.101 \\
(0.055)\end{array}$ & $\begin{array}{l}-0.094 \\
(0.056)\end{array}$ & $\begin{array}{c}0.012 \\
(0.060)\end{array}$ & $\begin{array}{l}-1.849 \\
(0.445)\end{array}$ & $\begin{array}{l}-2.177 \\
(0.485)\end{array}$ & $\begin{array}{c}0.394 \\
(0.491)\end{array}$ \\
\hline $00 \mathrm{~s}$ & $\begin{array}{l}-0.017 \\
(0.070)\end{array}$ & $\begin{array}{l}-0.020 \\
(0.071)\end{array}$ & $\begin{array}{c}0.099 \\
(0.076)\end{array}$ & $\begin{array}{l}-1.413 \\
(0.547)\end{array}$ & $\begin{array}{l}-1.819 \\
(0.572)\end{array}$ & $\begin{array}{c}0.768 \\
(0.601)\end{array}$ \\
\hline \multicolumn{7}{|l|}{ Region of origin (Yes/No) } \\
\hline Africa & & & $\begin{array}{c}0.109 \\
(0.039)\end{array}$ & & & $\begin{array}{c}0.451 \\
(0.359)\end{array}$ \\
\hline Asia & & & $\begin{array}{c}0.185 \\
(0.031)\end{array}$ & & & $\begin{array}{c}0.827 \\
(0.291)\end{array}$ \\
\hline Europe & & & $\begin{array}{c}0.099 \\
(0.029)\end{array}$ & & & $\begin{array}{c}0.157 \\
(0.309)\end{array}$ \\
\hline Middle-East & & & $\begin{array}{c}0.239 \\
(0.044)\end{array}$ & & & $\begin{array}{c}0.951 \\
(0.302)\end{array}$ \\
\hline North-America & & & $\begin{array}{l}0.115 \\
(0.030)\end{array}$ & & & $\begin{array}{c}0.204 \\
(0.326)\end{array}$ \\
\hline Pacific & & & $\begin{array}{c}0.108 \\
(0.029)\end{array}$ & & & $\begin{array}{c}0.095 \\
(0.360)\end{array}$ \\
\hline \multicolumn{7}{|l|}{ Children's characteristics } \\
\hline Male (Yes/No) & $\begin{array}{l}-0.019 \\
(0.012)\end{array}$ & $\begin{array}{l}-0.022 \\
(0.012)\end{array}$ & $\begin{array}{l}-0.022 \\
(0.012)\end{array}$ & $\begin{array}{l}-0.178 \\
(0.087)\end{array}$ & $\begin{array}{l}-0.191 \\
(0.088)\end{array}$ & $\begin{array}{l}-0.146 \\
(0.093)\end{array}$ \\
\hline Age in month & $\begin{array}{l}-0.001 \\
(0.002)\end{array}$ & $\begin{array}{l}-0.000 \\
(0.002)\end{array}$ & $\begin{array}{l}-0.001 \\
(0.002)\end{array}$ & $\begin{array}{c}0.003 \\
(0.017)\end{array}$ & $\begin{array}{l}-0.001 \\
(0.017)\end{array}$ & $\begin{array}{l}-0.006 \\
(0.018)\end{array}$ \\
\hline First cohort (Yes/No) & $\begin{array}{c}0.040 \\
(0.113)\end{array}$ & $\begin{array}{c}0.031 \\
(0.115)\end{array}$ & $\begin{array}{c}0.045 \\
(0.117)\end{array}$ & $\begin{array}{c}0.095 \\
(0.844)\end{array}$ & $\begin{array}{c}0.322 \\
(0.835)\end{array}$ & $\begin{array}{c}0.439 \\
(0.860)\end{array}$ \\
\hline$N$ & 1,942 & 1,942 & 1,942 & 1,942 & 1,942 & 1,942 \\
\hline Basic covariates & $\checkmark$ & $\checkmark$ & $\checkmark$ & $\checkmark$ & $\checkmark$ & $\checkmark$ \\
\hline Age at arrival FE & $\checkmark$ & $\checkmark$ & $\checkmark$ & $\checkmark$ & $\checkmark$ & $\checkmark$ \\
\hline $\begin{array}{l}\text { Cob FE } \\
\text { IV }\end{array}$ & $\begin{array}{l}\checkmark \\
\checkmark\end{array}$ & $\checkmark$ & $\checkmark$ & & $\begin{array}{l}\checkmark \\
\checkmark\end{array}$ & $\checkmark$ \\
\hline
\end{tabular}

Notes: See Table 1 notes, column (1), omitted category for regions is South America and 60s for arrival decade. Source: LSAC (2004-2016), ASJP linguistic data (v18), own calculations. 


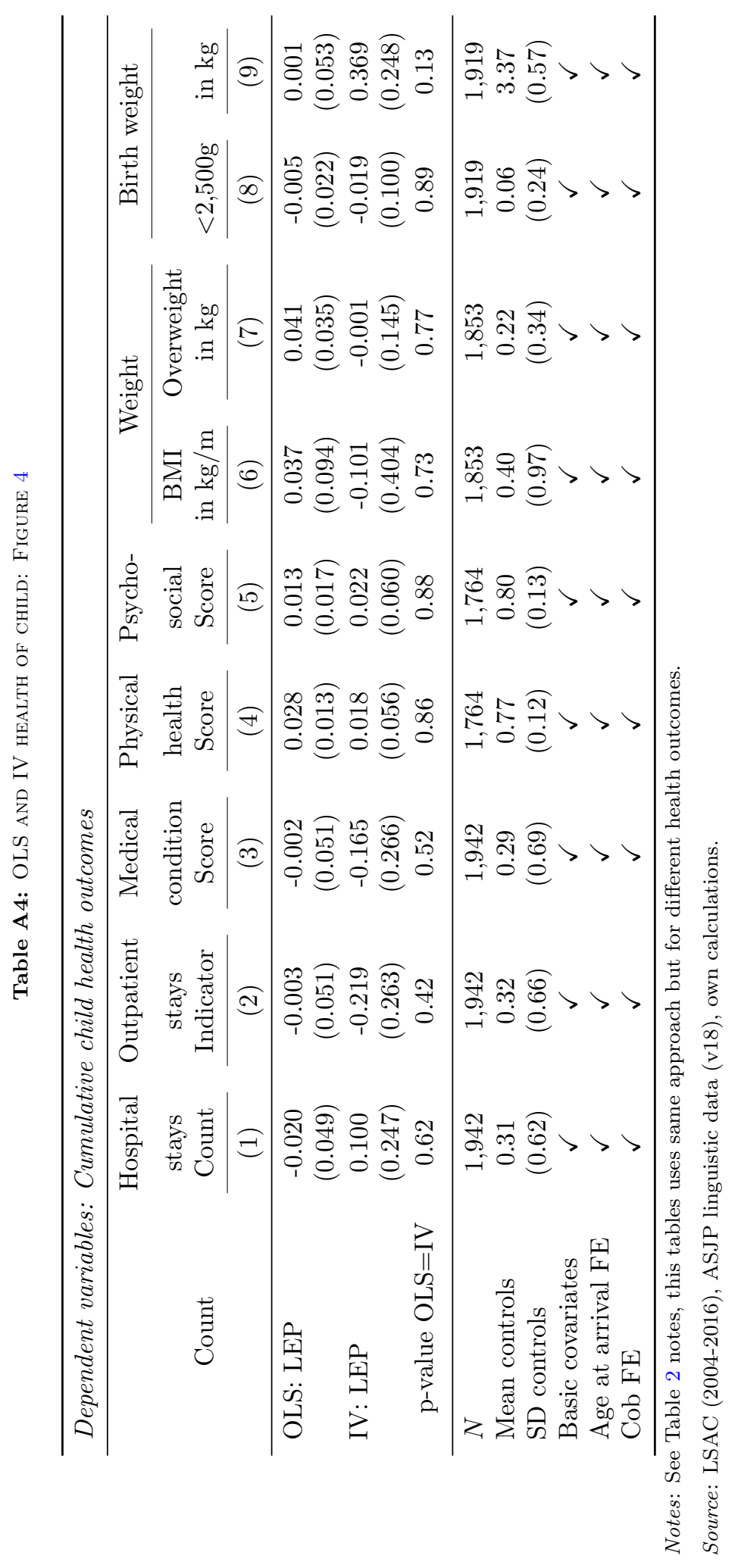




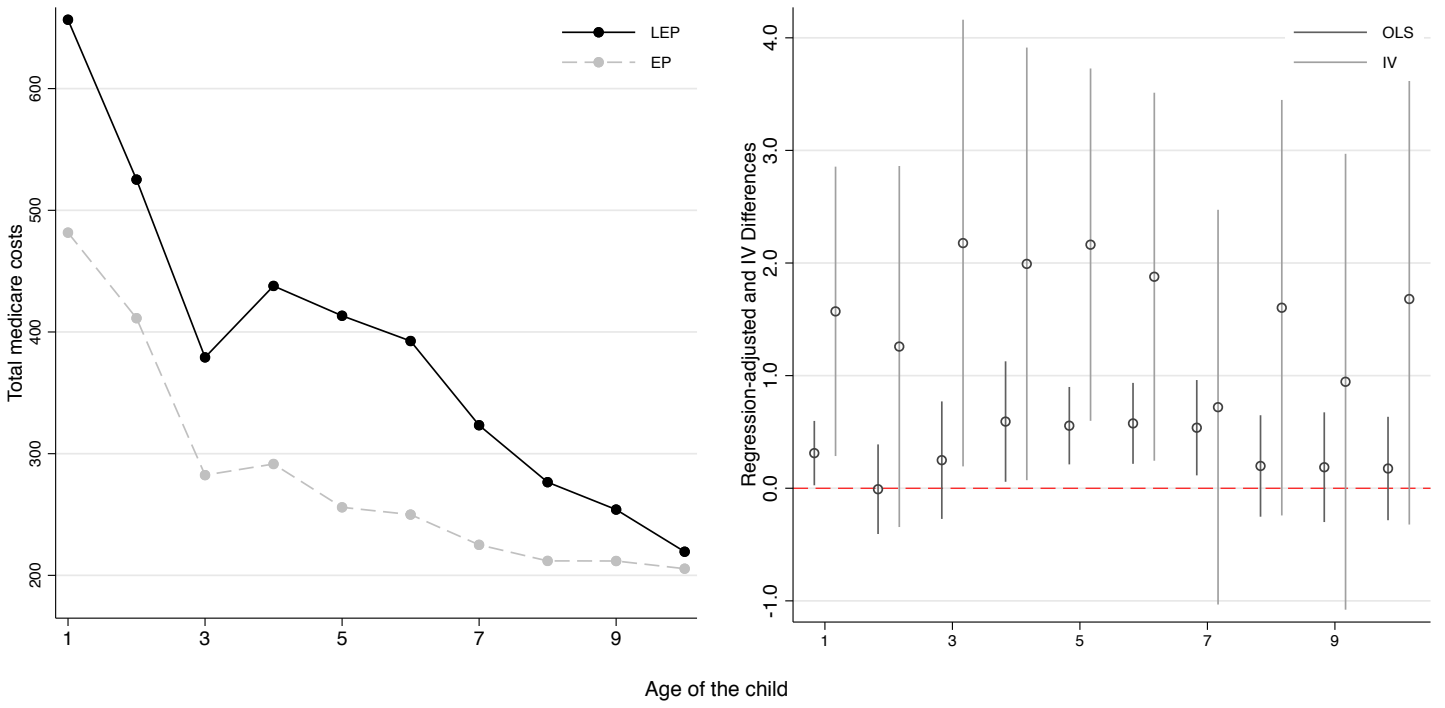

Figure A1: Average costs And REgression Results By CHILD'S AGE

Note: Note: The Figure plots in left average costs over the age of the child and on the right regression results, dark OLS and light IV.

Source: LSAC (2004-2016), ASJP linguistic data (v18), own calculations. 


\section{B Robustness}

First in Table B1, we present robustness of our OLS evidence in our main Table 1. Panel A tests if there are neglected non-linearities by first matching close subjects ( 5 nearest neighbours) to the LEP children based on a probit propensity score (see Table A3) (column 2). Using a similar aggregation that does not have the discontinuity at 5 comparable subjects, we use the (Epanechnikov) kernel matching (column 3). We then assess the common support (whether these subjects are comparable) and restrict the OLS estimation sample to those within the common support (again using the propensity score) (column 4). Next, we test whether our cost measure is an appropriate transformation (recall that we use $\log (\operatorname{costs}+1))$. Although there is quite a discussion in the literature around the appropriate treatment of cost measures, we chose to use the most simple specification and show robustness here. Column (5) uses the raw cost measure, column (6) the quasi maximum likelihood poisson regression that does not suffer from the 0-cost problem, or retransformation issues, and finally (7) uses the gamma regressions allowing for violations of the equidispersion-assumption in the poisson model.

Panel B presents sensitivity checks. First, whether there is meaningful heterogeneity in the lower tail of the language skill distribution, by whether or not the parent speaks English not at all. As expected, there is an additional penalty to not speaking at all, however, it is not significantly different (partly because this is a small group of parents). Similarly, if both parents have LEP there is an insignificant additional penalty. Results change little if we include all immigrant children (born overseas or living with their grandparents), whether we drop all people with missing values in any of the extended set of covariates, drop small-in-sample countries with $(<10)$ observations in our sample (note, these are not small countries, but have minor representation in our sample), or whether we group them into regions, i.e. if there are 4 people from Belgium and 2 from Romania, we create an indicator for Other European, and replace corresponding fixed effects with it.

Panel C, first regresses an indicator for whether the Medicare records could be linked to the survey responses. Recall that those with missing costs were dropped from our analysis - here we show there there is no differential selection into the sample. If anything, parents with LEP are more likely to have their records linked, although this is not statistically significant. Next, including regional controls (postcode fixed effects and a similarly-sized alternative local area measure to postcodes (SA3) fixed effects). These also make little difference to our main results.

Table B2 presents the Altonji-Elder-Taber bounds of Table 1 in greater detail. Panel A, contains those presented in the main text, Column (1) corresponds to the no selection on unobservables assumption, Column (2) presents the regression of the linear index of eq. (1) leaving out the LEP, and the second stage linear index of eq. (2) estimated in the propensity score regression (cf. in A3), which is the selection on observables upper bound. The remaining columns assume the selection on unobservables is (3) $25 \%$, , (4) $50 \%$, (5) $100 \%$, and (6) $200 \%$ the selection on observables (6). Panel B replicates these using the extended covariate set from Column (6) in Table 1.

In each panel we also estimate the Oster bound based on the same selection, but using the linear probability model in the first stage again represented as in 1 (Column 2). These results indicate no issues in using either the more reasonable binary nature or the linear approximation.

Turing to the robustness of our IV results, Figure B1 visualises the first stage using the alternative specifications of our instrumental variable (shown in Table 2). On the left, we present the linguistic distance determined by the first language spoken by the parent, rather than the main official language of the parent's COB (this corresponds to Column (5) of Table 2). On the right, we present the binary English- vs non-English-speaking COB (i.e., as used in Bleakley and Chin (2004) and shown in Column (2) in Table 2).

Table B2 illustrates robustness test for whether the immigrant parent came in a high migration wave from their respective COB. One difference between our IV set up and those used in the prior literature is that due to sample size restrictions, we cannot focus on childhood immigrants (i.e., those that immigrated before the age of 18). This increases the potential for selection based on gains, as older immigrants are more likely to choose where to go based on expected gains (although that would need to vary across sending countries to bias our results). The best we can do about this concern is to assess situations where there is arguably little room for selection. The figure plots high migration waves using the Census of 2011 (we only show the largest countries as examples). It is evident that some of these are driven by a mix of push (i.e. civil war) and pull (visa changes) but less related to the individuals decision making. We define a "high migration wave" dummy variable that is equal to 1 if the yearly migration was larger than 1.5 times the average migration from this COB (grey areas in the graph depict this). Table B3 tests the robustness of our main results by allowing the effect of LEP to vary by whether or not the parent immigrated during a high migration wave. We find no evidence for heterogeneity (this finding is robust to changes in the definition of a "high migration wave"), suggesting 
our results are not driven by selection on gains to immigrate.

Table B3 presents various tests of robustness of our main IV results. Column (1) presents our preferred specification. In columns 2-4, we conduct alternative tests to assess selection issues that may arise from including parents who immigrated as adults. First in column (2) we allow for two kinks in the IV using a second variable with $\max (0, A A-18)$ to capture a different slope for adult immigrants. With these two IVs the F-stat becomes more relevant, but it remains high. The result is almost indistinguishable from our main model. Next in Column (3) we include the full set of age at arrival fixed effects in the IVs to allow for a different impact on language proficiency at each age at arrival. Here, the F-stat indicates that there might be a weak IV problem, yet, results are comparable. In column (4), when we use groupings of the age at arrival dummies in the IVs, the F-stat gets slightly larger. Importantly, the main effect is robust to these age at arrival checks. As explained on the previous page we also tested heterogeneity in the effect due to arriving during a high migration wave (result is shown in Panel B, column 3). In Column (5) we estimate a Heckman-Lee type selection model and include the inverse mills ratio (similar to the bounding exercise above). As expected, the effect is of similar magnitude between the OLS and the IV and more significant (this is because we use more information than in the IV estimation by specifying the distribution in the first stage). Again the coefficient on the inverse mills ratio is only significant at the $10 \%$ significance level, as is the difference between OLS and IV in our main model, this again shows that there is little remaining evidence for selection on unobservables.

Panel B uses country of origin information to assess the possibility of alternative explanations for the significant language effects. Suppose that all linguistically far countries do not have a free or universal health care system, now parents from these countries (induced by the instrument) might not be accustomed to having free health care, and consequently overuse Medicare services. We find no evidence for such an idea, the interaction term is insignificant, and the effect is larger among immigrants that come from a free and universal health care system. Similarly, the effect is (highly) insignificantly different (although larger) for commonwealth countries, and below average GDP per capita (in sample). Note however, that due to our limited sample size, we are perhaps unlikely to reject such hypotheses.

Finally in Panel C. we follow Aoki and Santiago (2018) and include as an additional regressor the non-linear age at arrival specification in the first and second stage. To net out variation due to age at arrival effects specific to the country of origin, we include as an additional regressor, an interaction term of age at arrival and the following country of origin characteristics: GDP; genetic distance; and, \% of GDP spent on either health or education. the F-statistics are all strong, there is mild evidence for the OLS being substantially different from the IV, and the effect size is between our main results IV and OLS point estimates. 
Table B1: Testing functional form of main Results, Table 1

\begin{tabular}{|c|c|c|c|c|c|c|c|}
\hline & $(1)$ & $(2)$ & (3) & (4) & (5) & (6) & (7) \\
\hline \multicolumn{8}{|l|}{ A. Functional form } \\
\hline & & \multicolumn{2}{|c|}{ Matching } & \multicolumn{2}{|c|}{ OLS } & \multirow[b]{2}{*}{ Poisson } & \multirow[b]{2}{*}{ Gamma } \\
\hline & Baseline & $\begin{array}{c}5 \text { nearest } \\
\text { neighbours }\end{array}$ & $\begin{array}{c}\text { Epanech } \\
\text { Kernel }\end{array}$ & $\begin{array}{l}\text { Common } \\
\text { support }\end{array}$ & $\begin{array}{l}\text { Dollar } \\
\text { costs }\end{array}$ & & \\
\hline LEP & $\begin{array}{c}0.253 \\
(0.077)\end{array}$ & $\begin{array}{c}0.219 \\
(0.093)\end{array}$ & $\begin{array}{c}0.228 \\
(0.082)\end{array}$ & $\begin{array}{c}0.255 \\
(0.081)\end{array}$ & $\begin{array}{c}600.088 \\
(243.838)\end{array}$ & $\begin{array}{c}0.209 \\
(0.074)\end{array}$ & $\begin{array}{c}0.202 \\
(0.084)\end{array}$ \\
\hline $\mathrm{R}^{2}$ & 0.177 & & & 0.232 & 0.136 & & \\
\hline$N$ & 1,942 & 1,942 & 1,942 & 1,056 & 1,942 & 1,942 & 1,942 \\
\hline B. Sensitivity chec & $\begin{array}{l}1 / 2 \\
\text { Speaks not } \\
\text { at all } \\
\end{array}$ & $\begin{array}{l}\text { Both } \\
\text { parents }\end{array}$ & Include all & $\begin{array}{l}\text { Drop } \\
\text { missings }\end{array}$ & $\begin{array}{c}\text { Drop small } \\
\text { countries } \\
\end{array}$ & $\begin{array}{c}\text { Cluster small } \\
\text { countries }\end{array}$ & \\
\hline LEP & $\begin{array}{c}0.269 \\
(0.081)\end{array}$ & $\begin{array}{c}0.221 \\
(0.088)\end{array}$ & $\begin{array}{c}0.234 \\
(0.074)\end{array}$ & $\begin{array}{c}0.270 \\
(0.245)\end{array}$ & $\begin{array}{c}0.270 \\
(0.080)\end{array}$ & $\begin{array}{c}0.229 \\
(0.076)\end{array}$ & \\
\hline not at all & $\begin{array}{c}0.176 \\
(0.140)\end{array}$ & & & & & & \\
\hline both parents LEP & & $\begin{array}{c}0.104 \\
(0.127)\end{array}$ & & & & & \\
\hline $\mathrm{N}$ & 1,942 & 1,942 & 2,116 & 732 & 1,697 & 1,942 & \\
\hline $\mathrm{R}^{2}$ & 0.177 & 0.177 & 0.186 & 0.276 & 0.150 & 0.183 & \\
\hline C. Sensitivity chec & $\begin{array}{l}2 / 2 \\
\text { Medicare } \\
\text { available }\end{array}$ & $\begin{array}{c}\text { Postcode } \\
\text { Fixed Effects }\end{array}$ & $\begin{array}{c}\text { SA } 3 \\
\text { Fixed Effects }\end{array}$ & $\begin{array}{c}\text { Warmth \& } \\
\text { Overprotection }\end{array}$ & & & \\
\hline LEP & $\begin{array}{c}0.043 \\
(0.029)\end{array}$ & $\begin{array}{c}0.238 \\
(0.087)\end{array}$ & $\begin{array}{c}0.276 \\
(0.084)\end{array}$ & $\begin{array}{c}0.283 \\
(0.075)\end{array}$ & & & \\
\hline $\mathrm{N}$ & 2,136 & 1,942 & 1,942 & 1,942 & & & \\
\hline $\mathrm{R}^{2}$ & 0.100 & 0.332 & 0.316 & 0.197 & & & \\
\hline Basic covariates & $\checkmark$ & $\checkmark$ & $\checkmark$ & $\checkmark$ & $\checkmark$ & $\checkmark$ & $\checkmark$ \\
\hline Age at arrival $\mathrm{FE}$ & $\checkmark$ & $\checkmark$ & $\checkmark$ & $\checkmark$ & $\checkmark$ & $\checkmark$ & $\checkmark$ \\
\hline Cob FE & $\checkmark$ & $\checkmark$ & $\checkmark$ & $\checkmark$ & $\checkmark$ & $\checkmark$ & $\checkmark$ \\
\hline
\end{tabular}

Notes: See Table 1 notes, and discussion above.

Source: LSAC (2004-2016), own calculations. 
Table B2: Altonji Elder Taber \& Oster Bounds Table 1

\begin{tabular}{|c|c|c|c|c|c|c|}
\hline \multicolumn{7}{|c|}{ Dependent variable: Log total Medicare costs (in 2015 AUD) } \\
\hline & \multirow{2}{*}{$\begin{array}{c}\text { OLS } \\
(1)\end{array}$} & \multirow{2}{*}{$\frac{\text { Corr }}{(2)}$} & \multicolumn{4}{|c|}{ OLS + Inverse mills ratio } \\
\hline & & & (3) & (4) & $(5)$ & (6) \\
\hline $\begin{array}{l}\text { A. Main model } \\
\text { LEP }\end{array}$ & $\begin{array}{c}0.253 \\
(0.077)\end{array}$ & & $\begin{array}{c}0.234 \\
(0.081)\end{array}$ & $\begin{array}{c}0.215 \\
(0.081)\end{array}$ & $\begin{array}{c}0.176 \\
(0.081)\end{array}$ & $\begin{array}{c}0.099 \\
(0.081)\end{array}$ \\
\hline Oster bound & 0.253 & & 0.244 & 0.235 & 0.211 & 0.151 \\
\hline Selection on observables & 0.000 & $\begin{array}{c}0.051 \\
(0.006)\end{array}$ & 0.013 & 0.025 & 0.051 & 0.101 \\
\hline $\mathrm{R}^{2}$ & 0.177 & 0.031 & & & & \\
\hline \multicolumn{7}{|c|}{ B. Extended set of covariates } \\
\hline LEP & $\begin{array}{c}0.219 \\
(0.082)\end{array}$ & & $\begin{array}{c}0.202 \\
(0.086)\end{array}$ & $\begin{array}{c}0.186 \\
(0.086)\end{array}$ & $\begin{array}{c}0.153 \\
(0.086)\end{array}$ & $\begin{array}{c}0.087 \\
(0.086)\end{array}$ \\
\hline Oster bound & 0.219 & & 0.209 & 0.199 & 0.175 & 0.116 \\
\hline Selection on observables & 0.000 & $\begin{array}{c}0.047 \\
(0.007)\end{array}$ & 0.012 & 0.023 & 0.047 & 0.093 \\
\hline $\mathrm{R}^{2}$ & 0.231 & 0.021 & & & & \\
\hline $\mathrm{N}$ & 1,942 & 1,942 & 1,942 & 1,942 & 1,942 & 1,942 \\
\hline Basic controls & $\checkmark$ & $\checkmark$ & $\checkmark$ & $\checkmark$ & $\checkmark$ & $\checkmark$ \\
\hline Age of arrival FE & $\checkmark$ & $\checkmark$ & $\checkmark$ & $\checkmark$ & $\checkmark$ & $\checkmark$ \\
\hline Cob FE & $\checkmark$ & $\checkmark$ & $\checkmark$ & $\checkmark$ & $\checkmark$ & $\checkmark$ \\
\hline
\end{tabular}

Notes: See Table 1 notes, and discussion above.

Source: LSAC (2004-2016), own calculations. 

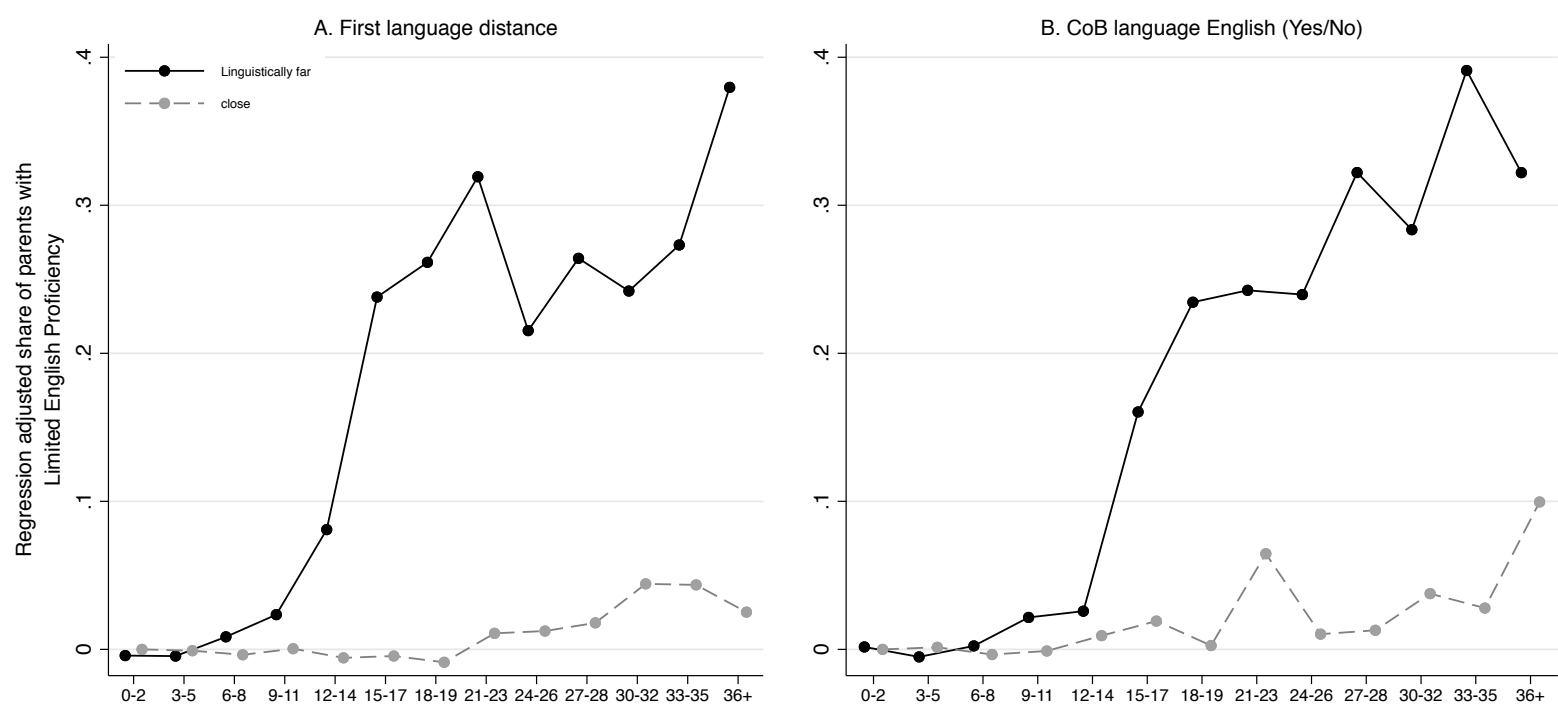

Parent's age of arrival (three year brackets)

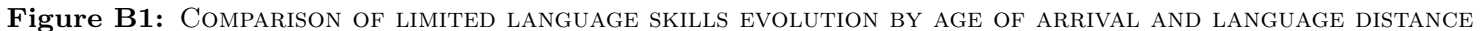
Note: See Figure 3 notes and discussion above.

Source: LSAC (2004-2016), ASJP linguistic data (v18), own calculations. 

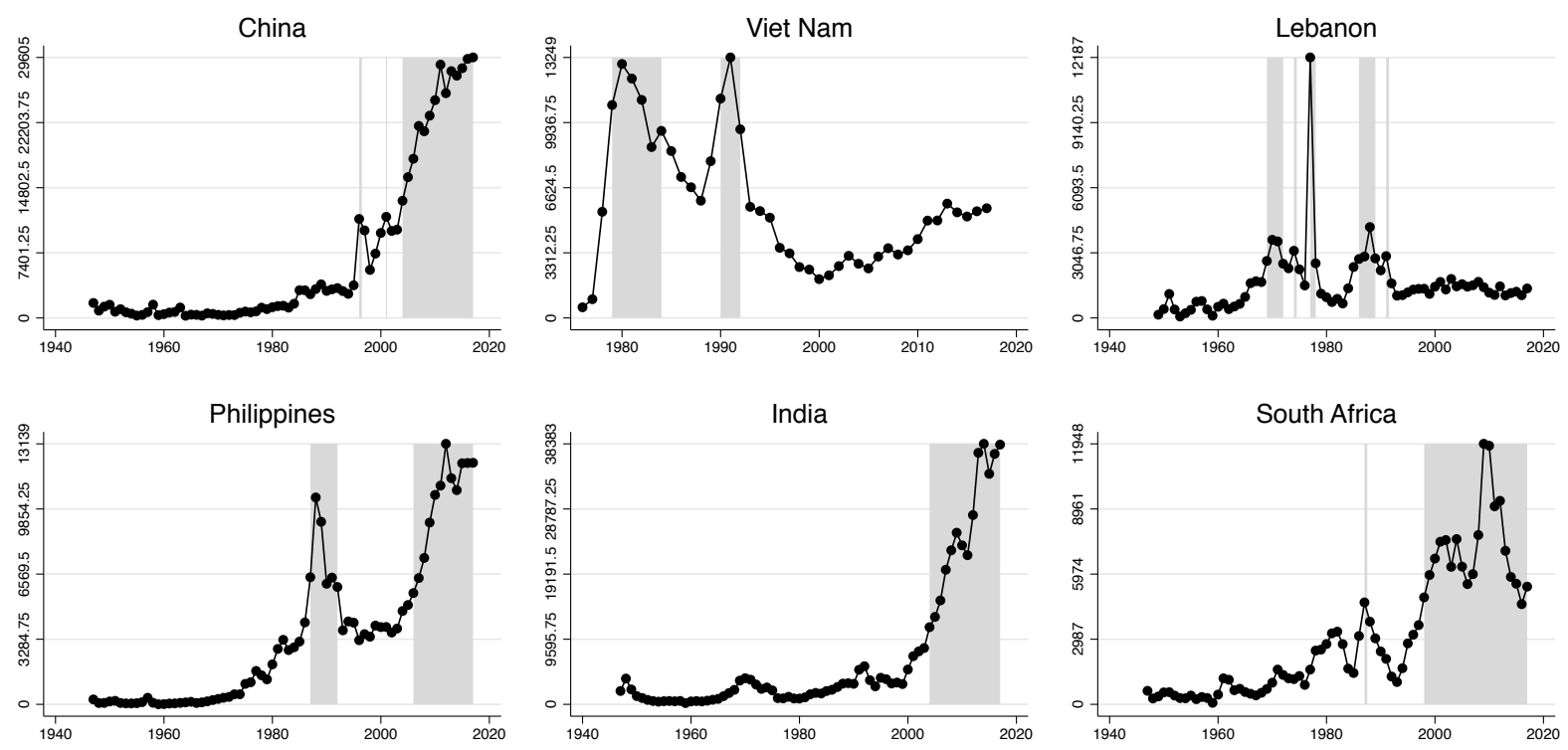

Figure B2: LARGES IN-SAMPLE COUNTRIES INFLOW IN AGGREGATE NUMBERS.

Note: The Figure plots "high migration wave" definition used in Table for the largest 6 origin countries in our data. Source: Census 2011, own calculations. 
Table B3: Testing Robustness of IV Results, Table 2

\begin{tabular}{|c|c|c|c|c|c|}
\hline & $(1)$ & $(2)$ & $(3)$ & $(4)$ & $(5)$ \\
\hline \multicolumn{6}{|l|}{ A. IV assumptions } \\
\hline & & \multicolumn{3}{|c|}{ Detailed Age Effects } & \multirow{2}{*}{$\begin{array}{l}\text { Control } \\
\text { function }\end{array}$} \\
\hline & Baseline & Two kinks & AA set & AA grouped & \\
\hline LEP & $\begin{array}{c}0.905 \\
(0.351)\end{array}$ & $\begin{array}{c}0.960 \\
(0.354)\end{array}$ & $\begin{array}{c}0.802 \\
(0.268)\end{array}$ & $\begin{array}{c}0.894 \\
(0.355)\end{array}$ & $\begin{array}{c}0.616 \\
(0.236)\end{array}$ \\
\hline$\lambda\left(z_{i}^{\prime} \gamma\right)$ & & & & & $\begin{array}{l}-0.249 \\
(0.150)\end{array}$ \\
\hline $\mathrm{N}$ & 1,942 & 1,942 & 1,942 & 1,942 & 1,942 \\
\hline $\mathrm{p}$-value $(\mathrm{OLS}=\mathrm{IV})$ & 0.050 & 0.060 & 0.239 & 0.094 & \\
\hline Fstat & 76.446 & 41.774 & 5.505 & 6.709 & \\
\hline \multicolumn{6}{|l|}{ B. Heterogeneity } \\
\hline & $\begin{array}{c}\text { Free + Univ } \\
\text { HCS }\end{array}$ & $\begin{array}{l}\text { Common- } \\
\text { wealth }\end{array}$ & $\begin{array}{c}\text { Came in low } \\
\text { migration times }\end{array}$ & $\begin{array}{c}\text { GDP } \\
\text { above average }\end{array}$ & \\
\hline LEP & $\begin{array}{c}0.557 \\
(0.281)\end{array}$ & $\begin{array}{c}0.454 \\
(0.333)\end{array}$ & $\begin{array}{c}0.780 \\
(0.392)\end{array}$ & $\begin{array}{c}0.995 \\
(0.336)\end{array}$ & \\
\hline $\mathrm{LEP} \times D_{k}$ & $\begin{array}{c}1.086 \\
(0.854)\end{array}$ & $\begin{array}{c}3.603 \\
(2.873)\end{array}$ & $\begin{array}{c}0.152 \\
(0.255)\end{array}$ & $\begin{array}{l}-0.288 \\
(0.670)\end{array}$ & \\
\hline Fstat & 9.978 & 1.624 & 38.215 & 14.541 & \\
\hline $\mathrm{N}$ & 1,942 & 1,942 & 1,942 & 1,942 & \\
\hline \multicolumn{6}{|c|}{ C. Controlling for: age at arrival $\times x_{k}$} \\
\hline & GDP & Distance & Health & Education & \\
\hline LEP & $\begin{array}{c}0.770 \\
(0.457)\end{array}$ & $\begin{array}{c}0.756 \\
(0.384)\end{array}$ & $\begin{array}{c}0.774 \\
(0.348)\end{array}$ & $\begin{array}{c}0.785 \\
(0.379)\end{array}$ & \\
\hline p-value $(\mathrm{OLS}=\mathrm{IV})$ & 0.222 & 0.177 & 0.115 & 0.088 & \\
\hline Fstat & 50.898 & 63.621 & 75.454 & 61.519 & \\
\hline $\mathrm{N}$ & 1,919 & 1,859 & 1,909 & 1,757 & \\
\hline Basic covariates & $\checkmark$ & $\checkmark$ & $\checkmark$ & $\checkmark$ & $\checkmark$ \\
\hline Age at arrival FE & $\checkmark$ & $\checkmark$ & $\checkmark$ & $\checkmark$ & $\checkmark$ \\
\hline Cob FE & $\checkmark$ & $\checkmark$ & $\checkmark$ & $\checkmark$ & $\checkmark$ \\
\hline
\end{tabular}

Note: See Table 2 notes and discussion above.

Source: LSAC (2004-2016), ASJP linguistic data (v18), various auxiliary datasets, own calculations. 


\section{Supplementary Data Sources}

In this appendix we detail the variables and the additional datasets we use. We also present descriptive statistics by the countries of origin used in our dataset.

Our main dataset is the Longitudinal Study of Australian Children (LSAC), which is merged with administrative Medicare records. We amend these most importantly with country of origin information, such as official language spoken, and the linguistic distance to English using the Automated Similarity Judgement Program (ASJP) v18. We include several complementary country of origin information as described below, such as genetic distance. Finally, for some of our heterogeneity analysis, we use area-level information from the Australian Census 2011, which we merge at either the postcode or SA3 area level (by parent's country of origin).

All dataset besides the LSAC+Medicare were deliberately chosen to be publicly available and we will make all extraction files as well as crosswalks available to researchers.

\section{ASJP}

For our IV estimation, we group countries by their language spoken. If the language is not English, we follow Isphording and Otten (2014) and Clarke and Isphording (2017), and use the Automated Similarity Judgement Program (ASJP) v18 Wichmann et al. (2010) to calculate the linguistic distance . Linguistic distance is based on the phonetic similarity of a 40 item word list between any language and English. This provides us with a continuous measure of linguistic distance, which in our sample, ranges from 0 (English) to 104.1 (Vietnamese). In our main specifications we categorise the parent's native language as English if English is an official language used in their country of birth (according to Wikipedia). Results do not differ if we instead only include countries that list English as their main language (see Table C.2 below for the full list). Additionally, like Clarke and Isphording (2017), we set the parent's native language to English if the first language the parent learned was English (reported by the parent in LSAC). When the parent's language is English according to these definitions, the linguistic distance is 0 .

We also calculated the linguistic distance based on the parent's first language spoken (instead of the official language of their country of birth), and used this as an alternative measure in robustness models. This is a more precise measure of the linguistic distance of the parent's first language. However, for our IV, we are interested in capturing variation in exposure to the English language, which is arguably better captured by the linguistic distance based on a country's official language. The continuous ASJP linguistic distance measures are derived from Wichmann et al. 2010 for version 18. See Holman et al. 2008, 2011 for the original development and Isphording and Otten (2014) for a detailed description.

The data is publicly availably via: https://asjp.clld.org/download, we use data accessed on the 17.10 .2018

We further tested our results using the classifications of Krieger, Renner and Ruhose (2018) who made theirs publicly available (here we also tested another linguistic distance measure based on language trees), neither affected our main conclusions. As both datasets use a classification based on different definitions of what constitutes an English speaking country our results are thus also robust to our definition.

\section{Other parental country of birth information}

[Genetic distance] Most similar to our linguistic distance measure is the genetic distance measure. In a robustness check we assess whether it matters to control for its interaction with age at arrival. We use the original data by Spolaore and Wacziarg (September 2017).

The data is publicly availably via: http://sites.tufts.edu/enricospolaore/, we use data accessed on the 17.10.2018.

[Commonwealth] We use to classify the commonwealth status of the countries in a robustness check.

The data is publicly availably via: http://thecommonwealth.org/member-countries, we use data accessed on the 17.10.2018. 
[Free and Universal Health Care Systems] We use a classification of the health care system of countries in a robustness check.

The data is publicly availably via: http://globalresidenceindex.com/hnwi-index/health-index/, we use data accessed on the 29.10.18.

[GDP/Expenditure] We use GDP and expenditure for health and education measures provided by the World Bank, for corresponding robustness checks.

The data is publicly availably via: wdi.worldbank.org/, we use data accessed on the 29.10.18.

\section{Australian Bureau of Statistics (ABS)}

We used several statistical data sources from the ABS.

[High migration wave] to assess which immigrants are likely to select to come to Australia by their age we use the arguably exogenous events, that is we compiled for each country of origin the high migration wave as shown in Figure B2. The data is merged to the individual by origin and year of arrival which gives us a dummy for whether the parent came in a high migration wave.

We use the "historical-migration-statistics.xls" from

https://www.homeaffairs.gov.au/about/reports-publications/research-

statistics/statistics/live-in-australia/historical-migration-statistics (Accessed 02.10.2018).

[Australian Census 2011] To construct the local availability of networks, we merge parent by home country and local area (SA3).

1. Number of people from origin in postcode: "Language by postal area - ABS 2001 census" 2011 Census "Counting Employed Persons, Place of Work" https://www.abs.gov.au/websitedbs/censushome.nsf/home/tablebuilder

2. Number of medical practitioners and teachers from the same origin country.

Same data as in 1. Accessed 06/11/2018 (Medical practitioners - OCCP Occupation equal to "Medical Practitioners" by SA3) and 22/02/2019 (teachers - INDP Industry of Employment equal to "Combined Primary and Secondary Education" by SA3). 


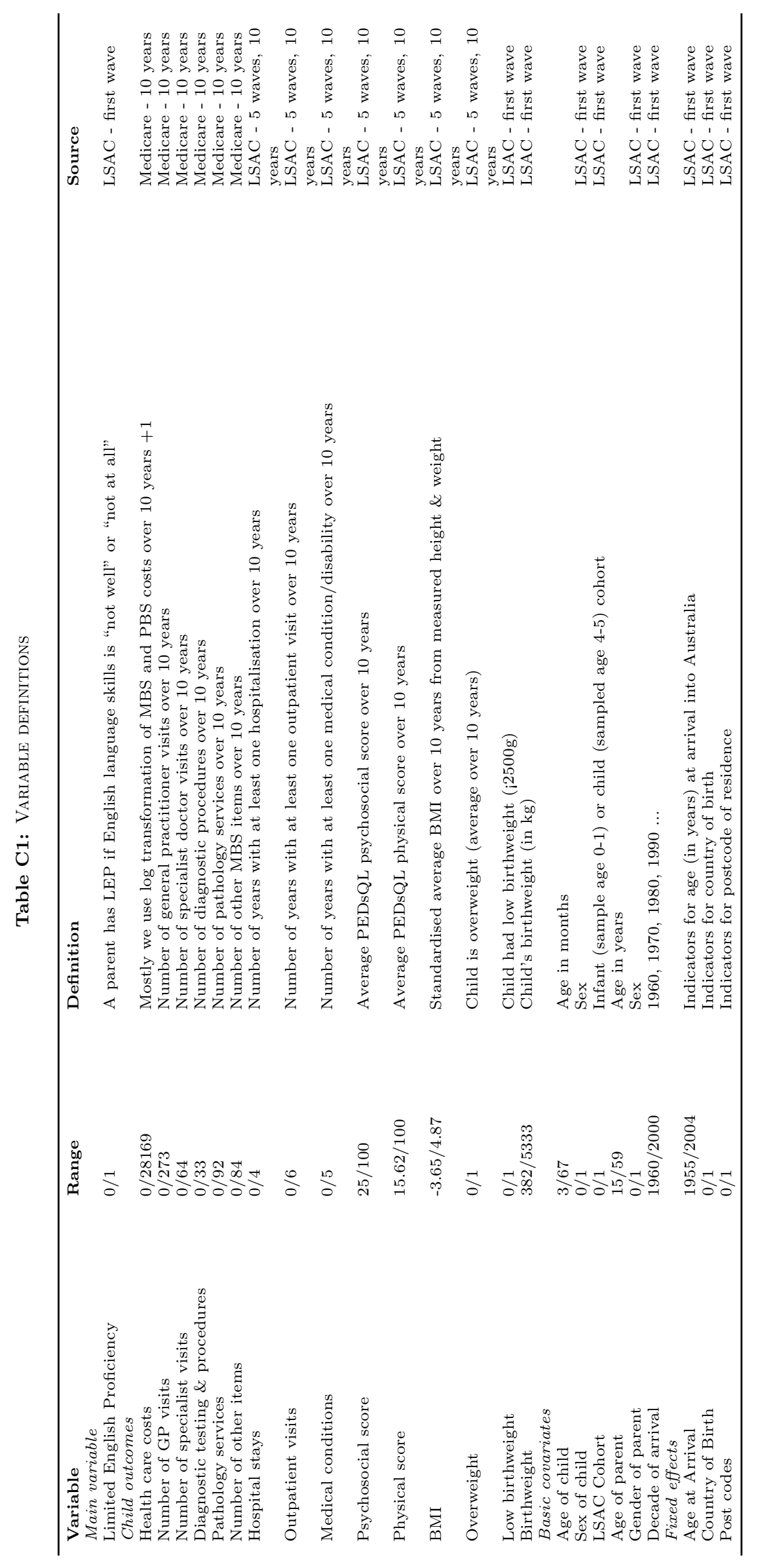




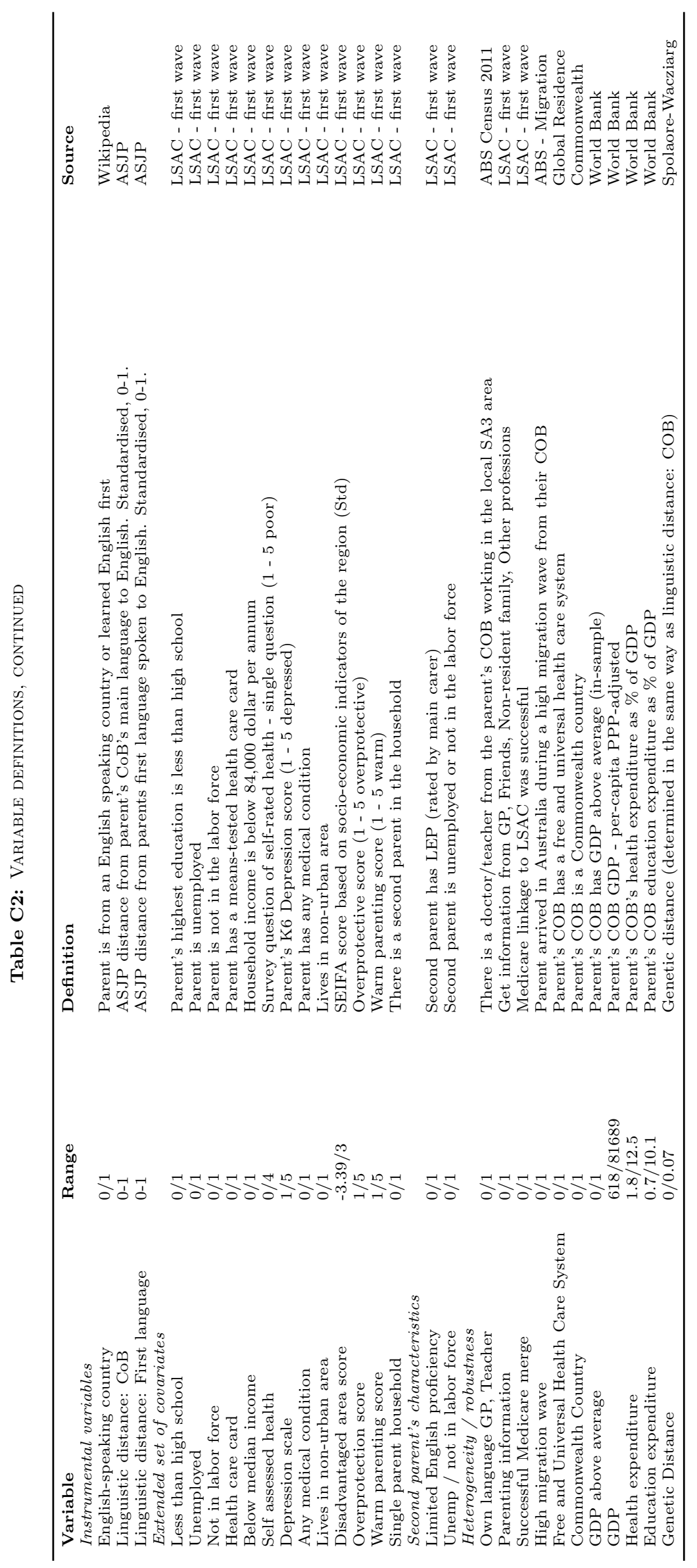




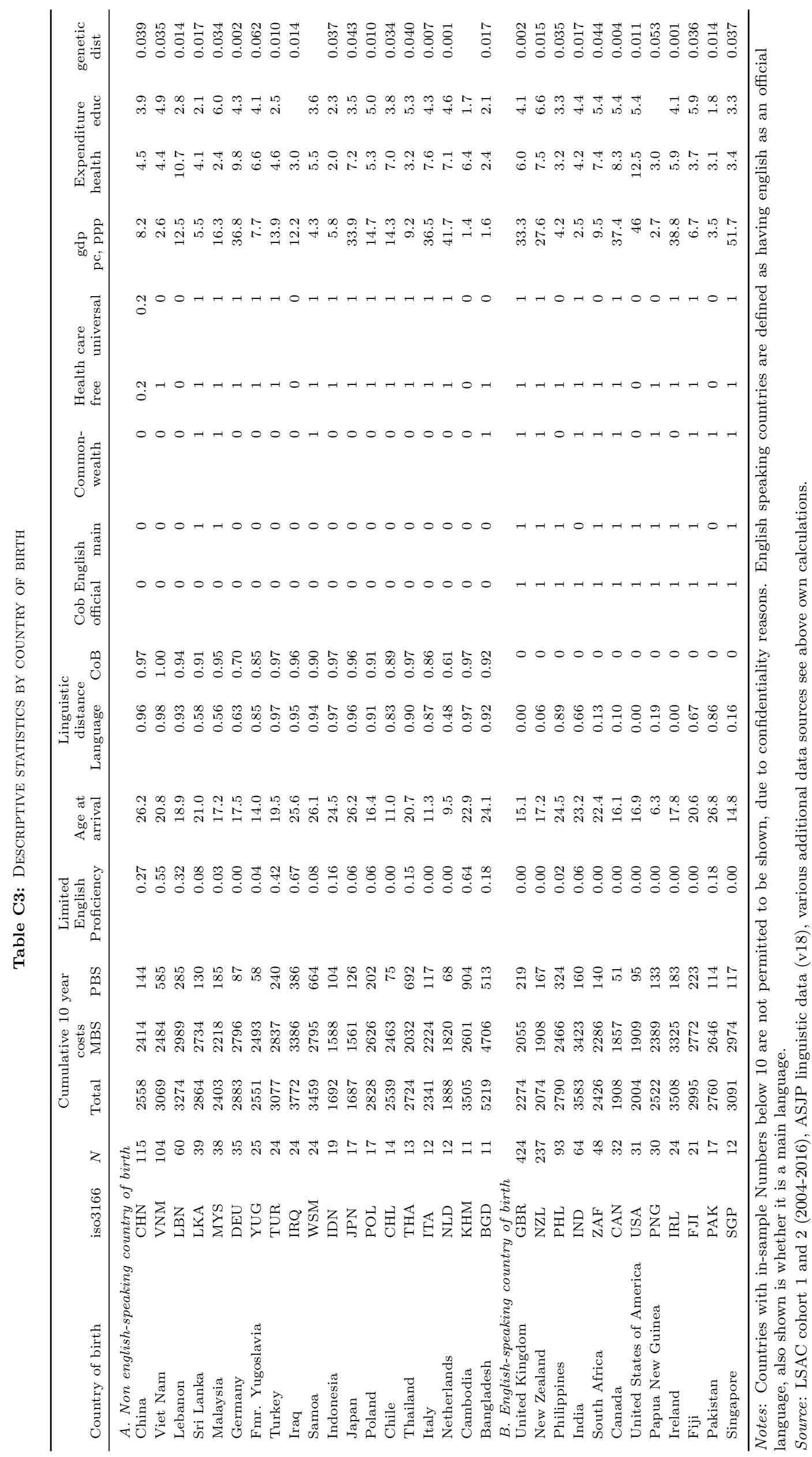

